\title{
Targeting and Activity-related Dendritic Modification in Mammalian Retinal Ganglion Cells
}

\author{
Richard J. T. Wingate and lan $\mathrm{D}$. Thompson \\ University Laboratory of Physiology, Oxford University, Oxford OX1 3PT, United Kingdom
}

We have studied factors that influence the development of dendritic morphology in hamster retinal ganglion cells. By combining fluorescent retrograde tracing with in vitro Lucifer yellow injection into fixed retina, cells with appropriate and inappropriate visuotopic projections have been compared. In adult hamsters, cells with an aberrant ipsilateral projection from the nasal retina display a uniformly sparse dendritic morphology. However, following monocular enucleation at postnatal day $\mathbf{O}(\mathrm{PO})$, this population displays a significantly enhanced dendritic complexity in the adult. By contrast, removal of one eye at P6 or at P12 produces progressively less effect. These results suggest that dendritic complement of the adult aberrant projection can be regulated by altering the early postnatal axonal environment.

The development of aberrant ganglion cells was investigated to determine the relative influences of cell death and dendritic remodeling in shaping the composition of the adult aberrant population. Aberrant cells were found to be indistinguishable from other cells in nasal retina throughout early development. After ganglion cell death (P1-P12) is over, aberrant cells still display a full range of cell types. However, at eye opening (P16) they undergo a rapid loss of dendritic complexity by remodeling. By P22, aberrant cells display a uniformly sparse dendritic morphology. When hamsters were raised in the dark between P12 (the end of ganglion cell death) and P22, this severe remodeling was blocked. This block was maintained when hamsters were dark reared to P42. Hence, both dark rearing and monocular enucleation at PO produce similar effects on the development of visuotopically inappropriate hamster retinal ganglion cells.

We speculate that the patterns of dendritic sculpting that we have observed reflect activity-mediated modulation of dendritic form via retrograde signals from the terminal arbors. This has implications for retinal ganglion cell morphological classification and, more generally, for mechanisms that influence the dendritic development of other neurons in the CNS.

\footnotetext{
Received Oct. 6, 1993; revised Mar. 28, 1994; accepted May 5, 1994

This work was supported by the Medical Research Council of the UK through Project Grant G9013416N, with the kind loan of computing equipment provided by Programme Grant PG7900491. We would like to thank Dr. Thomas FitzGibbon for his comments on the manuscript. R.J.T.W. was in receipt of an MRC scholarship.

Correspondence should be addressed to Dr. Richard Wingate, UMDS, Guy's Hospital, London Bridge, London SE1 9RT, UK.
}

Copyright (C) 1994 Society for Neuroscience $0270-6474 / 94 / 146621-17 \$ 05.00 / 0$
IKey words: superior colliculus, retrograde tracers, Lucifer yellow, decussation, monocular enucleation, dark rearing, fractal dimension, aberrant development]

Retinal ganglion cells have provided a useful model for investigating the development of precise and characteristic morphologies in central neurons. In particular, the relative contributions of extrinsic factors and intrinsic "blueprints" to the emergence of morphological classes have been widely discussed (for an overview, see Chalupa and Dreher, 1991). For example, retinal ganglion cell axons develop stereotyped adult axonal morphologies from initially more exuberant projections. Individual axons may display early transient branches to inappropriate target nuclei (Ramoa et al., 1989; Bhide and Frost, 1991; R. J. T. Wingate and I. D. Thompson, unpublished observations). Within a target, immature axons may be topographically inaccurate (Simon and O'Leary, 1992) or terminate in the wrong laminae (Sretavan and Shatz, 1984). Finally, the precise, classspecific morphology of axonal arbors emerges only relatively late in development (Sur et al., 1984). It is also clear that the processes that refine ganglion cell axons may be mediated by spontaneous (pre-eye opening) or visually driven correlated retinal activity (Archer et al., 1982; Sur et al., 1982; Kalil et al., 1986; Shatz and Stryker, 1988; Sretavan et al., 1988; Hahm et al., 1991).

By comparison, dendritic development in retinal ganglion cells is less well understood. While it has been convincingly demonstrated that retinal ganglion cell dendrites show a degree of territorial "competitive" behavior in defining the extent of their dendritic arbors (Perry and Linden, 1982; Eysel et al., 1985; Leventhal et al., 1988), the complexity of branching within these territories appears to be intrinsically determined (Montague and Friedlander, 1989, 1991; Sakaguchi, 1989). This is despite the observation that all mammalian retinal ganglion cells appear to undergo a period of dendritic elaboration followed by pruning (cat: Dann et al., 1987, 1988; Ramoa et al., 1987, 1988; rabbit: Wong, 1990; rat: Perry and Walker, 1980; Yamasaki and Ramoa, 1993; hamster: Lau et al., 1992; ferret: Wingate and Thompson, unpublished observations). Various studies have sought an explanation for retinal ganglion cell dendritic remodeling (Lau et al., 1990, 1991; Wong et al., 1991). A strong temporal correlation points to exuberant growth and remodeling being intimately involved with synaptogenesis (Wässle, 1988). The implicit assumption is that dendritic remodeling will hence be regulated intraretinally (Bodnarenko and Chalupa, 1993) to the exclusion of target influences. However, exuberant dendritic "spines" are not overt synaptic sites (Wong et al., 1992), nor is their removal influenced by patterns of retinal activity (Lau et 
Table 1. For each experimental group, the number of animals used is shown along with the total number of cells that were fully analyzed

\begin{tabular}{llcl} 
& Group & Animals & Cells \\
\hline Developing & P1 & 5 & $41(16)$ \\
& P6 & 4 & $68(36)$ \\
P12 & 3 & $33(27)$ \\
P14 & 2 & $40(20)$ \\
P16 & 5 & $21(13)$ \\
P22 & 3 & $31(22)$ \\
Adult & P22 dark & 5 & $28(28)$ \\
& Normal & 23 & $71(36)$ \\
& En0 & 11 & $30(30)$ \\
& En6 & 6 & $18(18)$ \\
& En12 & 3 & $21(21)$ \\
& P42 dark & 3 & $15(15)$
\end{tabular}

The number of aberrant cells within each total is shown in parentheses. A small proportion of the P12 sample came from P1 3 hamsters. Similarly, a small number of the ordinary ganglion cells in the P22 sample came from a P20 hamster. Eyeopening is at P15/16 in the hamster. Cells from the P16 sample hence came from both hamsters with partially and fully opened eyes. Hamsters are sexually mature at $\mathbf{P 4 2}$.

al., 1990; Wong et al., 1990) or "dendritic competition" (Lau et al., 1991). In the following study, we present evidence that large-scale dendritic remodeling in central neurons can be strongly influenced by the environment at the axonal terminals.

By using a combination of retrograde tracer (rhodamine latex microspheres; Katz et al., 1984) and intracellular Lucifer yellow injection in fixed tissue (Dann and Buhl, 1987), we can first label projection populations and then sample their detailed dendritic morphology (Ramoa et al., 1987, 1988; Wingate et al., 1992). We have focused upon one particular population of visuotopically inappropriate ganglion cells in the nasal retina. They are distinct from their retinal neighbors in that they project ipsilaterally, rather than to contralateral targets. Birthdating studies by Reese et al. (1992) suggest that this population of ganglion cells should display a variety of dendritic morphologies. However, the adult nasal ipsilateral projection is represented by a single, distinct, sparsely branching dendritic class (Wingate and Thompson, 1989). We examine the emergence of this morphology and the consequences for normal development of manipulating terminal interactions either by early monocular enucleation, or by altering normal retinal activity by dark rearing.

\section{Materials and Methods}

A total of 47 adult hamsters and 27 hamster pups were used for these studies (see Table 1). For neonatal surgery, hamsters at P0 or P5 were anesthetized by ether inhalation, while older animals (P11-P21) received an injection of a dilute solution (1:4) of alphaxalone $0.9 \%$ and alphadolone 0.3\% (Saffan, Pitman-Moore, Uxbridge, UK; i.m., equivalent dose of $2 \mathrm{ml} \mathrm{kg}{ }^{-1}$ at full concentration). For adult surgery, hamsters were anesthetized with pentobarbitone sodium (Sagatal, RMB Animal Health Limited, Dagenham, UK; $60 \mathrm{mg} \mathrm{kg}^{-1}$ ). In one group of animals, monocular enucleations of the right eye were performed at P0, P6, and $P 12$. In a second group, hamster pups were placed with their mothers in the dark at P12. The latter subsequently received only a limited exposure to light, during anaesthesia and the injection of retrograde tracer ( $24 \mathrm{hr}$ before perfusion), and during the administration of a lethal overdose. A third group of hamsters was raised without any manipulation prior to retrograde tracer injection.

Tracer injections were made into monocular animals at adulthood, into dark-reared animals at P21 and at P42 and into normal hamsters at a range of postnatal ages, $1 \mathrm{~d}$ prior to intracellular injection of retinal ganglion cells (see Table 1). After craniotomy, the cortex overlying the thalamus and midbrain was aspirated, and multiple injections of rhodamine latex microspheres (Lumafluor Inc., New York) were made unilaterally into the visual pathways, under air pressure through fine glass pipettes (total volume of 0.7-3.0 $\mu$ l depending on age).

Animals were killed by an overdose of pentobarbitone sodium (Sagatal, RMB Animal Health Limited, Dagenham, UK; $120 \mathrm{mg} \mathrm{kg}$ ) after appropriate survival times ( $1 \mathrm{~d}$ in neonates, and up to $5 \mathrm{~d}$ in adults). The retinas were lightly fixed by intracardial perfusion with $1 \%$ paraformaldehyde in $0.1 \mathrm{~m}$ phosphate buffer, dissected out, and flatmounted in $0.1 \mathrm{M}$ phosphate buffer to be examined under UV epifluorescence. Retrogradely labeled cell bodies were identified and selectively impaled with glass micropipettes. Cells were then iontophoresed with Lucifer yellow (Sigma; $15 \%$ in $0.1 \mathrm{M} \mathrm{LiCl}$; Ramoa et al., 1988) and their detailed dendritic morphologies were reconstructed from serial photomicrographs. A small number of the cclls were found not to be double labeled with retrograde tracer on later inspection $(17 \%$ of all neonatal cells and $3 \%$ of adult cells). Because cells with an appropriate decussation pattern are the vast majority of all ganglion cells, such singlelabeled neurons were included in the nonaberrant ganglion cell sample, providing that a sufficient length of axon was visible to distinguish them from amacrine cells. The numbers of fully reconstructed cells are given in Table 1. An image analysis system (Seescan plc, Cambridge, UK) was used to measure soma area, arbor area and the number of dendritic terminal segments, or tips, in reconstructed cells. The fractal dimension (Mandelbrot, 1977), a scale-independent measure of dendritic branching complexity, was calculated by a pixel dilation protocol (Flook, 1978). Full details of the methods of intracellular injection and morphological analysis are given elsewhere (Wingate et al., 1992). Tracer injection sites wcre cxamined to cnsurc that beads had not crossed the midline.

\section{Results}

Projection populations of retinal ganglion cells were always initially identified by making multiple injections of fluorescent tracer (rhodamine latex beads) unilaterally into the thalamus and mid-brain of adult and neonatal hamsters. A total of 418 cells were then intracellularly injected with Lucifer yellow, drawn from serial photomicrographs, and digitized for quantitative analysis. The pattern of ganglion cell body labeling in the retina following unilateral retrograde tracer injection reflects the pattern of axonal decussation at the optic chiasm. Figure 1 shows the labeling pattern in an adult animal. Bead-filled ganglion cells are found across the whole of the contralateral retina. In the retina ipsilateral to the injection sites, the majority of labeled cells were limited to a distinct temporal crescent. A small population of cells outside the temporal crescent, in nasal retina, is also labeled and constitute the nasal ipsilateral projection.

To discriminate between populations of cells with different projections, we use the term ordinary to describe retinal ganglion cells with axon targeting that is appropriate for binocular vision. These comprise the contralateral projection and the ipsilateral projection from the temporal crescent. This population contains a heterogeneous mix of cell classes, which we group together on the basis of their axonal targets. The ipsilateral projection outside the temporal crescent is described as aberrant in that, unlike other nasal retinal ganglion cells, their axons fail to cross the midline at the chiasm and therefore the majority cannot make congruent binocular visual maps. While such a projection is anomalous in terms of conventional visual pathways, an obscure functional role cannot be completely excluded and this possibility is further considered in the discussion.

The following results are divided into three parts. In the first section, the range of retinal ganglion cell types found in normal adult hamster is described. We bricfly discuss the problems of using subjective and objective measures of cell type and compare the populations of ordinary and of aberrant ganglion cells. In the second section, the morphology of cells within the nasal 
aberrant ipsilateral projection are examined in adult animals that have had one eye removed at P0, P6, or P12 (En0, En6, and En 12 , respectively). Finally, we compare the morphological development of cells in nasal retina that have an aberrant ipsilateral projection with that of ordinary retinal ganglion cells, and we investigate the effect of dark rearing on aberrant cell development after the period of ganglion cell death is over.

\section{Retinal ganglion cells in normal, adult hamsters}

Normal adult hamster retinal ganglion cells can be divided into three broad classes on the basis of their dendritic morphology. We use the classification system of Perry (1979), which identifies rodent retinal ganglion cells as types I, II, and III. Figure $2 A$ shows examples of ordinary cells that represent these broadly defined groups.

Type I cells (Fig. 2Ai,ii) have a high degree of dendritic complexity with an open branching structure that is similar to that of type $I$ cells in the rat. As in the rat, there appears to be a morphological diversity within this group. Type I hamster cells can either have regularly branching arbors (Fig. 2Ai) or more disordered, curvy dendritic branching (Fig. 2Aii). This appears to correlate with the division of the rat type I group into respectively, $\alpha$-cells (Peichl, 1987; Fukuda et al., 1988) or $\delta$-cells (Peichl, 1989). We did not attempt the neurofibrillar stains that would provide a diagnostic test for presence of $\alpha$-cells (Peichl et al., 1987) and discriminate them from $\delta$-cells. In addition, we did not identify inner as opposed to outer stratifying retinal ganglion cell types. In the rat, stratification of subtypes provides an additional source of heterogeneity within the type I class (Fukuda et al., 1988; Peichl, 1989).

Type II cells are typified by tightly branching dendritic trees that are generally smaller than neighboring type I cells (Fig. 2 Aiii $-v)$. These cells are homologs of type II cells in the rat (Perry, 1979) and are reminiscent of the "tight" $\gamma$-cell morphologies found in the $\gamma$-cell cluster in the ferret (Wingate et al., 1992). Cells within the type II division bear the greatest number of short dendritic spines, although spine coverage is neither even throughout the dendritic tree, nor universal among type II cells. Although type II cells are characteristically asymmetric (as in the rat, Yamasaki and Ramoa, 1993), the direction of axonal outgrowth is independent of the axis of dendritic asymmetry. There is no class of cells in the hamster that could be described as homologous to the carnivore $\beta$-cell.

Type III cells (Fig. $2 A v i, v i i)$ have sparsely branching dendritic trees with a low dendritic territorial coverage. Again, this class displays a strong homology with the equivalent type III cells in the rat retina (Perry, 1979).

Quantifying dendritic morphology. While the dendritic archetypes of each class as represented in Figure $2 A$ are distinct from one another, the borders between types of cell are blurred at their extremes. Complex type I cells resemble type II cells, while sparse type I cells overlap the most complex type III cells. Ordinary populations of retinal ganglion cells are composed of a mixture of different classes of dendritic arbors within a continuous variation. To avoid problems associated with spurious classifications, we use a scale-independent measure of dendritic complexity, the fractal dimension $\left(D_{f}\right)$, to compare the dendritic composition of heterogeneous populations as a whole (Wingate et al., 1992). In this way statistical comparisons of morphological differences are made possible. But how good are such parameters in replicating observer categorization?

Quantitative and qualitative approaches are compared in Fig-
RETROGRADE TRACER - FLUORESCENT BEADS

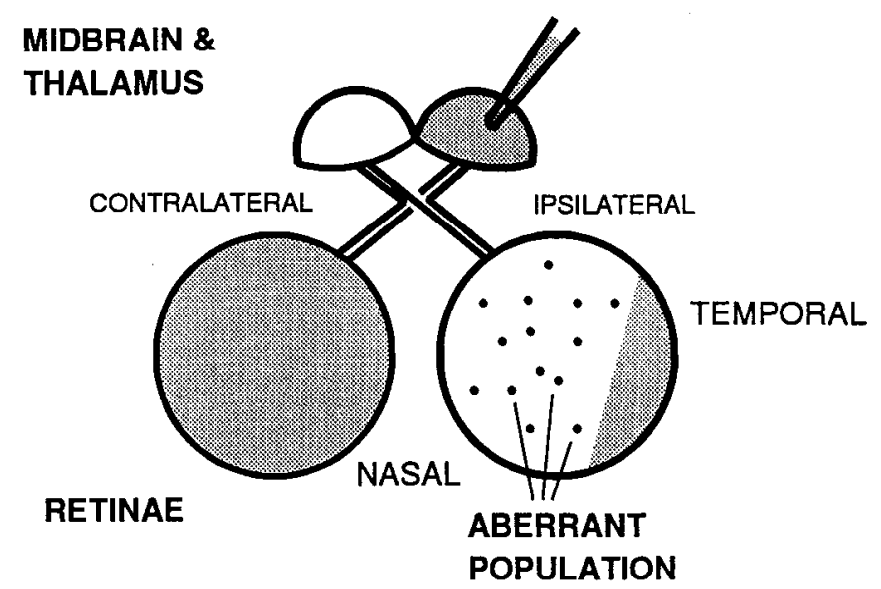

Figure 1. Schematic diagram showing how different populations of retinal ganglion cells are identified by their projections. Unilateral multiple injections of rhodamine fluorescent beads are made into the midbrain and thalamus. The beads are subsequently taken up by ganglion cell axon terminals from both retinas. The contralateral retina is uniformly covered by labeled cell bodies, but in the ipsilateral retina labeled cells are concentrated in a temporal crescent. A small number of labeled cells lie outside the ipsilateral temporal crescent and comprise the $a b$ errant population (the size of this population peaks at around 1400 cells by $\mathrm{P} 4$, but by $\mathrm{P} 12$ it is in the adult range of $200-300$ cells; I. D. Thompson, P. M. Cordery, and C. E. Holt, unpublished observations).

ure $2 B$, in which fractal dimension is plotted against soma size for each member of the population of ordinary retinal ganglion cells. The different symbols represent cell type as scored by three observers (further details in the figure caption) and the size of the symbol increases with the degree of observer concordance. A cell for which there is no observer agreement is reduced to a single point. Overall agreement between observers is highly significant ( $K=0.61$, where $K$ varies from 0 , no agreement, to 1 , complete concordance; $z=7.3 ; p<0.0001$; Siegel and Castellan, 1988).

It is clear that fractal dimension offers a simple parameter by which to separate type III cells from type I and type II. Above fractal dimensions of around 1.25 , most cells are subjectively classified into the latter classes. It is also clear that ambiguities increase as type III cells become quantitatively more complex. Within the band of higher fractal dimensions, type I and type II cells were sufficiently distinct to be subjectively identified on the basis of branching style alone. In the hamster, soma size does not offer a useful means of discriminating between cell classes.

The aberrant nasal ipsilateral projection. Figure, $3 A$ shows a representative sample of retinal ganglion cells that could be demonstrated to contribute axons to the aberrant ipsilateral projection from outside the retinal temporal crescent. It is immediately apparent that the overriding majority of these cells have a type III dendritic morphology (Fig. $3 A i-i v, v i)$. Occasional examples of cells with a higher dendritic coverage are found (Fig. $3 A v$ ), but never any cells that would correspond to the most complex type II dendritic morphology. Figure $3 B$ shows the subjective identification of these cells in the plot of soma size against fractal dimension. As for ordinary cells, the fractal dimension is again a robust predictor of type III morphologies. As $D_{f}$ rises above $D_{f}=1.25$, cells are scored as type I. It is interesting that observer concordance in identifying more com- 

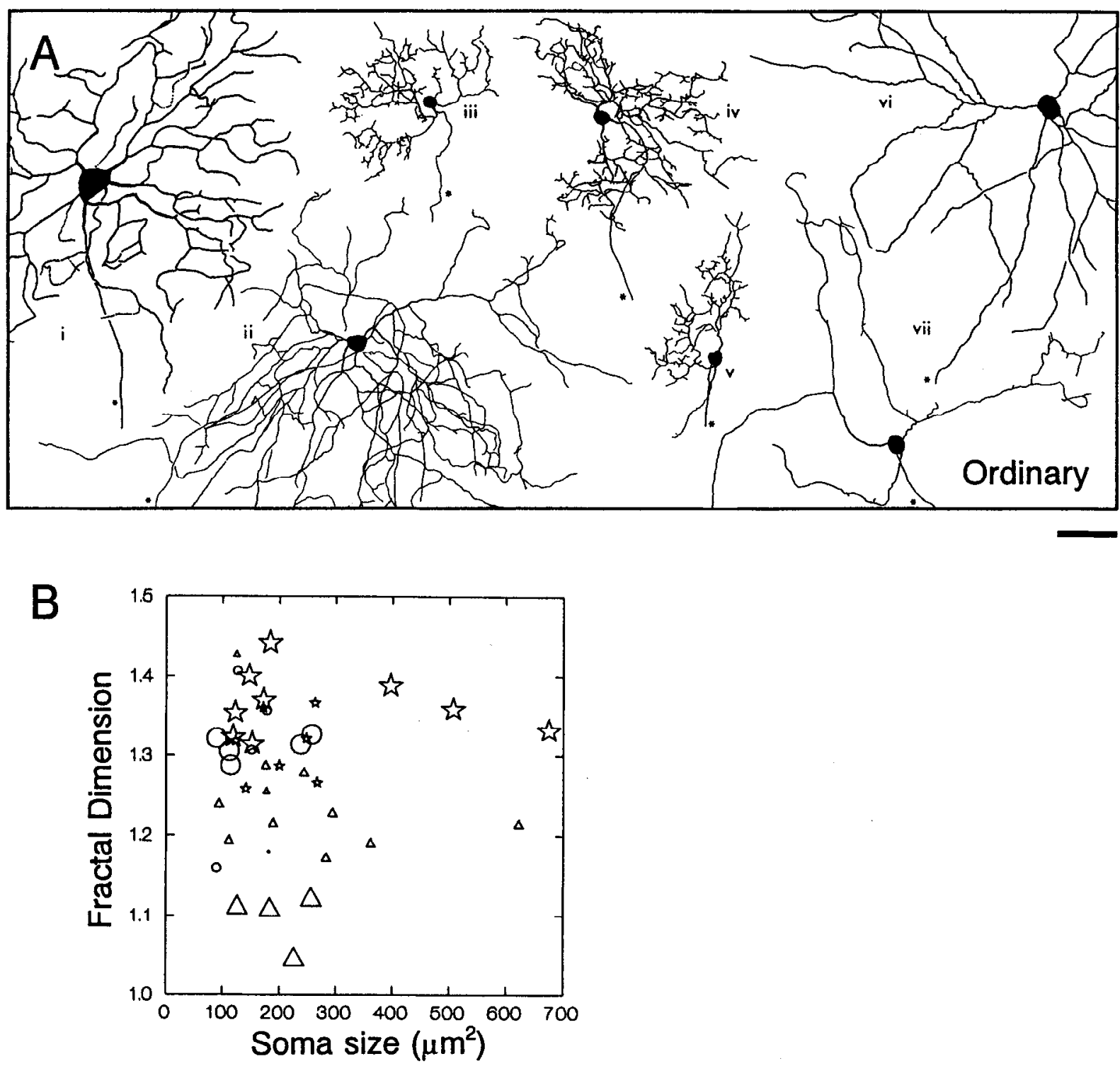

Figure 2. A, Ordinary hamster retinal ganglion cells: drawings made from serial photomicrographs of Lucifer yellow-filled cells with appropriate visuotopic projections. Retinal ganglion cells of type I ( $i$ and $i i)$, type II ( $i i i-v)$, and type III cells (vi and vii) are shown. Asterisks denote axons. Scale bar, $50 \mu \mathrm{m} . B$, Fractal dimension is plotted against soma size for each of ordinary cells that were reconstructed. Symbols represent different cell types as scored by three independent observers (star, type I; circle, type II; triangle, type III). Symbol size is proportional to the level of agreement between the observers (largest, complete concordance; intermediate, two of three; dot, no agreement). Cells were viewed at random and embedded within a much larger number of dendritic arbors from different populations. All cells were magnified to the same size for scoring cell type.

plex, "borderline" aberrant type III cells (of $D_{f}=1.2$ ) was greater than for ordinary type III cells. While the delimiting upper values of type III complexity remained identical between populations, the confidence in defining cells above this level as nontype III is less than for ordinary cells. Comparing the aberrant and ordinary populations, the median fractal complexity of aberrant ganglion cell dendritic arbors $\left(D_{f}=1.133\right)$ is significantly lower than that of ordinary retinal ganglion cells $\left(D_{f}=1.307 ; z\right.$ $=4.157 ; p<0.00006$, for a two-tailed Wilcoxon-Mann-Whitney test; Siegel and Castellan, 1988). There is no significant difference in the median value of the soma size or arbor size between aberrant and ordinary cell samples.

\section{The nasal ipsilateral projection in monocular animals}

The implication of the previous section is that ganglion cells projecting ipsilaterally from nasal retina constitute a distinct morphological class. Is this association of dendritic morphology and trajectory at the chiasm inevitable? Normal decussation patterns can be perturbed by monocular enucleation early in development. Removal of one eye at birth in the hamster results in an enlarged uncrossed projection from the remaining eye: fewer retinal ganglion cells die and the distribution of terminals remains exuberant (Frost et al., 1979; Rhoades, 1980; Hsiao, 1984; Insausti et al., 1984, 1985; So et al., 1984; Woo et al., 1985; Thompson, Cordery, and Holt, unpublished observations). Later enucleations have progressively less effect. Enucleation at $\mathrm{P} 6$ leaves uncrossed cell numbers only slightly increased but stabilizes an exuberant terminal distribution, whereas, after cnucleation at $\mathrm{P} 12$, the remaining uncrossed projection resembles that in normal adults (Hsiao, 1984; Thompson, Cordery, and Holt, unpublished observations). We have examined the morphologies of ipsilaterally projecting ganglion cells in adult 

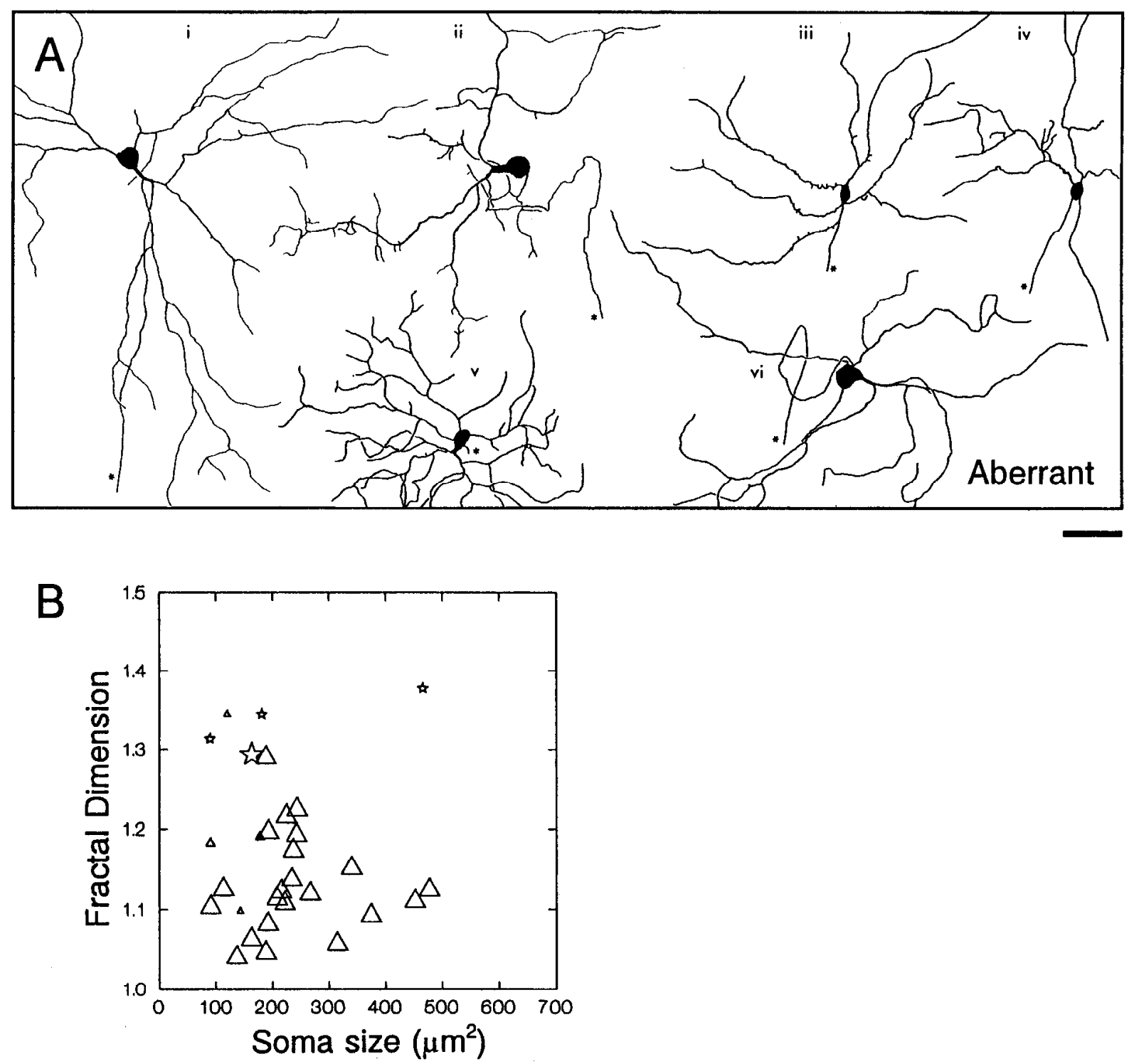

Figure 3. A, Retinal ganglion cells with an aberrant ipsilateral projection from nasal retina. The majority of cells are classified as type III ( $i-i v$ and $v i$ ). Cell $v$ would be classified as type I. Asterisks denote axons. Scale bar, $50 \mu \mathrm{m}$. B, Fractal dimension is plotted against soma size for each aberrant cell. Symbols represent different cell types as scored by three independent observers (star, type I; circle, type II; triangle, type III), and symbol sizes are proportional to the level of agreement between the observers. Aberrant cells were assessed "blind" from a larger mixed population.

monocular animals that had been enucleated at P0 (En0), at P6 (En6) or at P12 (En12). In this section we will only discuss the morphologies of the aberrant retinal ganglion cells from nasal retina, examples of which are shown in Figure 4.

Figure $4 A$ shows representative cells from the aberrant ipsilateral projection in adult hamsters monocularly enucleated at P0 (En0). The number of cells with this projection is approximately twice as great as normal and it is immediately apparent that the diversity of cell types represented in the population is also increased. Cells corresponding to the full range of type $\mathbf{I}$ (Fig. 4Aiii, iv,vi), type II (Fig. 4Aii,v,vii), and type III (Fig. 4Ai) dendritic morphologies are represented in the aberrant population. None of the individual cells would be distinguishable from a neighboring, ordinary cell in nasal retina.

Figure $4 B$ shows representative morphologies of En 6 aberrant cells that display a greater dendritic diversity than normal. Like the En 0 monocular enucleate hamster, the incidence of aberrant cells with a type I morphology (Fig. 4Bi,ii) is greater than in unoperated animals, although the most regular and " $\alpha$ "-like of type I cells were not encountered in our sample. Unlike the En0, type II cells (Fig. 4Biii) that display a tight, spiny dendritic arbor were very rare. The proportion of sparsely branching, type III cells (Fig. $4 B$ ) with an aberrant projection is closer to that in intact animals.

Figure $4 C$ shows representative aberrant cells from adult En 12 hamsters. Unlike the aberrant population of the En6, the majority of cells are type III. In this sense, aberrant cells in the En 12 are indistinguishable from those in a normal adult animal.

Further quantitative analysis is presented in Figure 5, which plots fractal dimension against soma size for the En0, En6, and En 12 populations of aberrantly projecting cells (A, B, and C, respectively). As in Figures $2 B$ and $3 B$, symbol type indicates cell class, while symbol size indicates the degree of concordance between observers in this subjective classification. In the En0 population of aberrant ganglion cells (Fig. $5 A$ ), the number of cells with a high value of fractal dimension is obviously in- 

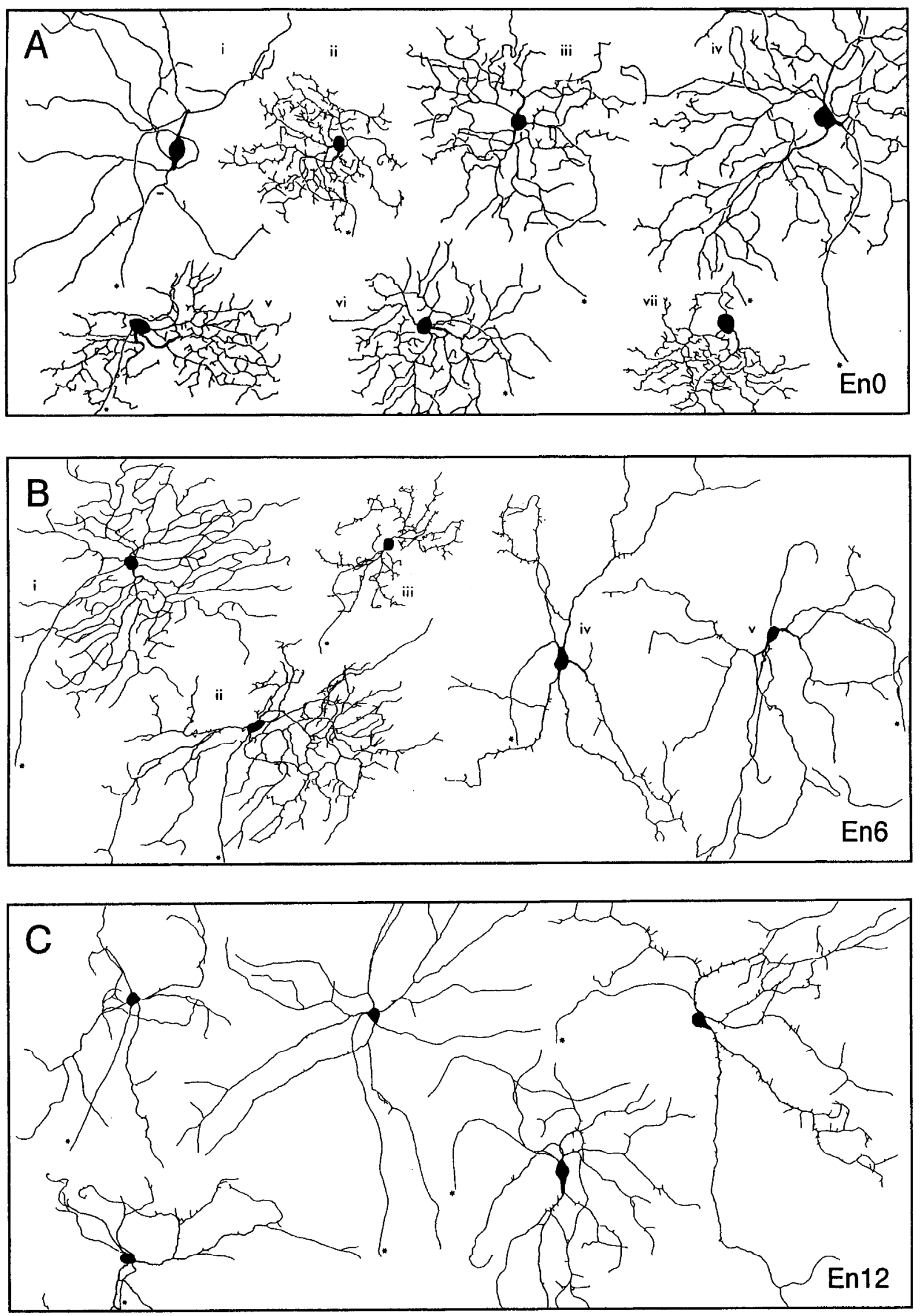

Figure 4. Retinal ganglion cells with an aberrant ipsilateral projcction from nasal retina in the remaining cyc of hamstcrs monocularly enucleated at $\mathrm{P} 0, \mathrm{P} 6$, and P12. A, Representative sample of aberrant cells from an adult En0 hamster. A variety of cell types are represented; type I (iii, iv, 
creased, reflecting the increased diversity of cell types. The median fractal dimension $\left(D_{f}=1.272\right)$ of dendritic arbors in the En0 population is significantly higher than in unoperated animals $(z=2.38 ; p=0.017$, in a two-lailed Wilcoxon-MannWhitney test). The same plot for En6 animals (Fig. $5 B$ ) reveals an even distribution of dendritic complexities across the range of fractal dimensions, but the increase in median fractal dimension $\left(D_{r}=1.194\right)$ and hence dendritic coverage, was not significant at the $5 \%$ level $(z=1.88, p=0.061)$. Observer classification confirms the paucity of type II morphologies among more complex aberrant cells in the En6 sample. Aberrant cells in En 12 animals (Fig. $5 C$ ) do not have a significantly higher median fractal dimension $\left(D_{f}=1.192\right)$ compared to that in intact animals $\left(D_{f}=1.133: z=1.17, p=0.095\right)$. However, a statistical comparison of the number of terminal segments in the En 12 $($ median $=28)$ and intact aberrant population (median $=16.5)$ reveals an increase in complexity at a higher significance $(z=$ $2.11, p=0.035$ ). This suggests an increase in small branches that are too short to contribute significantly to the coverage of the arbor. To summarize, monocular enucleation at $\mathrm{PO}$ results in a numerically expanded population of aberrant cells projecting from nasal retina that, in terms of diversity of dendritic morphology, is essentially indistinguishable from the ordinary appropriate projection. Later enucleations generate decreasing diversity in the aberrant population. Is it possible that the diversity revealed by enucleation might be briefly apparent at some early postnatal stage? To investigate the developmental potential of the nasal ipsilateral projection, the postnatal development of ordinary and aberrant cells is contrasted in the following section.

\section{Postnatal dendritic development}

Postnatal development of ordinary hamster retinal ganglion cells and of ganglion cells with an aberrant projection, were examined at P1, P6, P12, P14, P16, and P22. In interpreting changes in the composition of retinal ganglion cell populations through development, it is important to note that retinal ganglion cell death occurs postnatally and is effectively over by P12 in the hamster (Sengelaub and Finlay, 1981, 1982; Insausti et al., 1984; Tay et al., 1986; Thompson, Cordery, and Holt, unpublished observations). Within this period, the retina itself undergoes a rapid increase in its surface area (between P6 and P12) while eye-opening occurs at $\mathrm{P} 15 / 16$.

Ordinary cells. The development of ordinary retinal ganglion cells is shown in Figure 6. At P1, hamster retinal ganglion cells are still in a very immature phase of development (Fig. 6A). Median soma size $\left(61.35 \mu \mathrm{m}^{2}\right)$ and arbor size $\left(2087 \mu \mathrm{m}^{2}\right)$ are considerably smaller than in adult cells $\left(180.9 \mu \mathrm{m}^{2}\right.$ and 28,090 $\mu \mathrm{m}^{2}$, respectively). Dendritic arbors are generally sparse and typified by asymmetric branching where a small number of longer processes of variable lengths are elaborated by short sidebranches. The limited diversity of dendritic branching styles does not conform to any adult classification. The length of terminal segments can be much greater than the internodal dis-
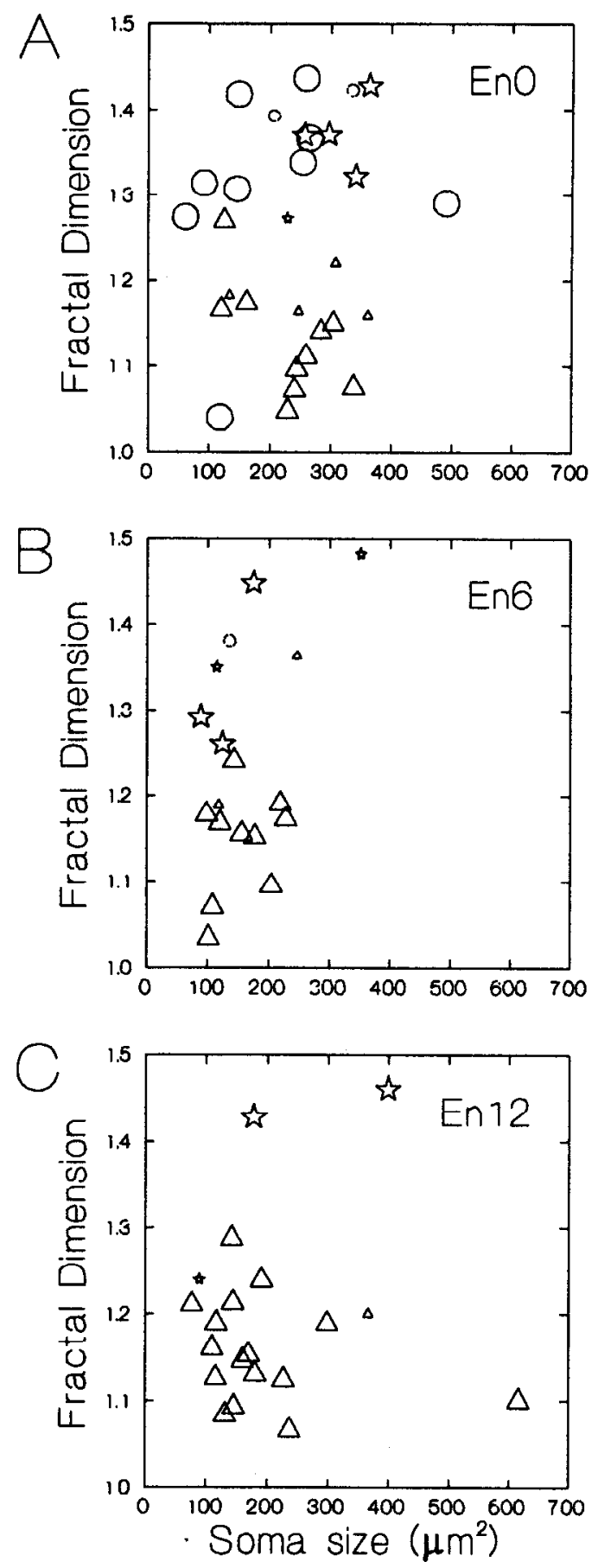

Figure 5. Fractal dimension plotted against soma area (in $\mu \mathrm{m}^{2}$ ) for aberrant cells with an ipsilateral projection from nasal retina in adult monocular hamsters. $A$, EnO aberrant cells show a similar distribution to ordinary cells. $B$, The En 6 distribution shows less diversity and fewer complex cell types. $C$, The En 12 aberrant distribution is very similar to that in an intact animal. Symbols correspond to cell type as defined by observers (star, type I; circle, type II; triangle, type III), and symbol size is proportional to the degree of observer concordance.

$v i)$, type II ( $i i, v, v i i)$, and type III $(i)$. These cells are identical to ordinary ganglion cells with appropriate connectivity. $B$, Representative aberrant cells from an adult En6 hamster: type I cells ( $i$ and $i i)$, type II cells (iii), and type III cells ( $i v$ and $v$ ) are present in the nasal ipsilateral projection. $C$, Representative cell drawings showing the range of aberrant cell arbors in an adult En 12 retina. The lack of diversity and predominance of type III morphologies are similar to that in an intact hamster. The presence of dendritic spines on a number of aberrant En 12 dendritic arbors is noticeable at closer inspection. Dendritic spines are associated with immature dendrites in many mammalian retinas, but are also retained into adulthood in individual ganglion cells of various classes. Asterisks denote axons. Scale bar, $50 \mu \mathrm{m}$. 

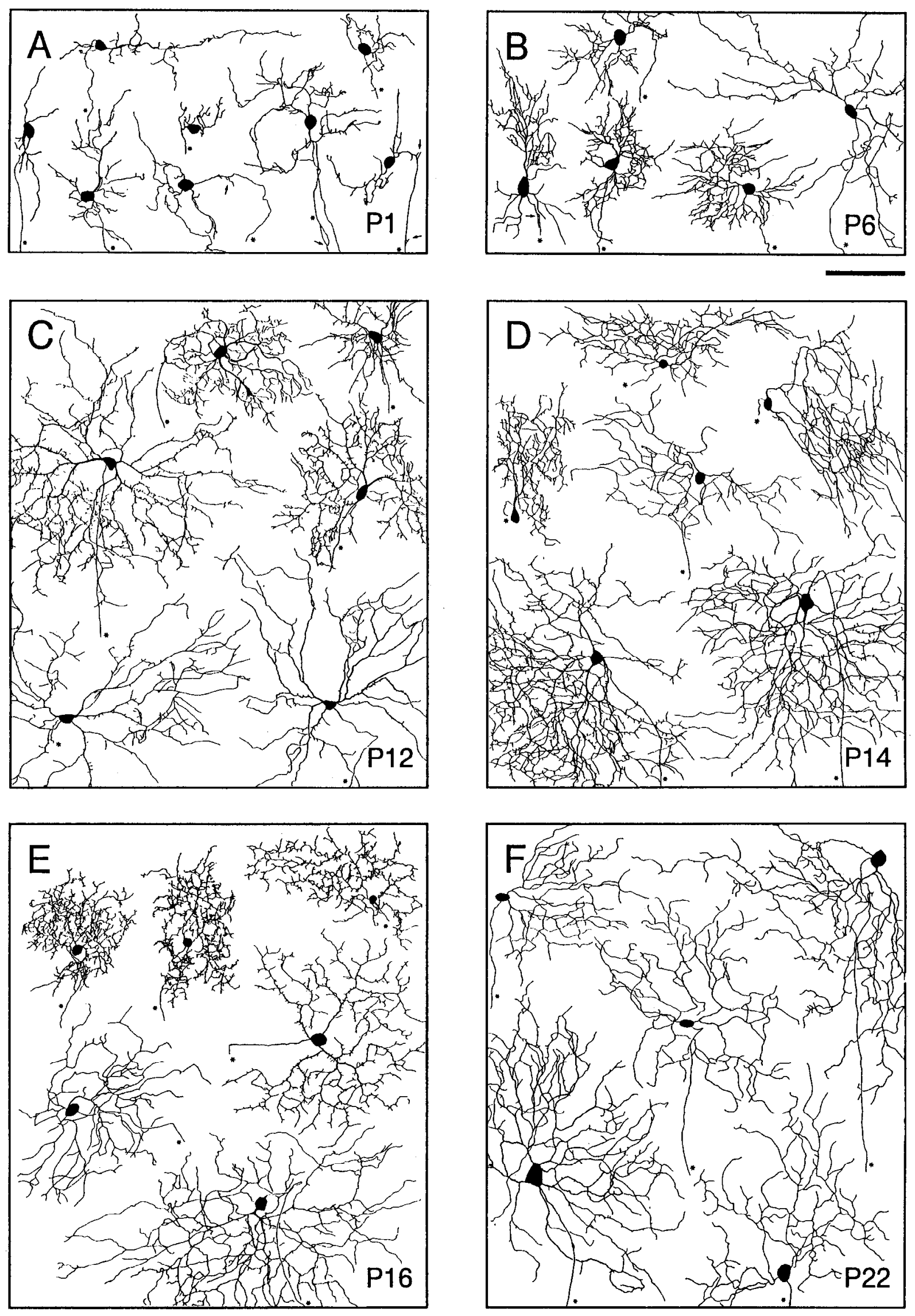
tances, and dendritic tips occasionally end in swellings that might correspond to growth cones. Axons show unique features associated with their immaturity. Many Pl ganglion cells display short axonal side-branches close to the cell body (indicated by arrows in Fig. 6A) and occasionally even intraretinal axonal bifurcations. High-power photomicrographs in Figure $7, A$ and $B$, contrast two $\mathrm{Pl}$ cells with different degrees of primitive dendritic arborization. In Figure $7 B$, small axonal spines elaborate the first $5 \mu \mathrm{m}$ of the axon initial segment, which is shown in the inset (bottom right) at a higher power. While axonal spines are transient, large initial corrections in retinal axon trajectory that are evident in some cells (such as Fig. $7 B$ ) persist through to adulthood.

Retinal ganglion cells at P6 still show relatively little diversity of branching style and do not fall into adult retinal ganglion cell classes (Fig. $6 B$ ). Cell soma sizes (median $=54.56 \mu \mathrm{m}^{2}$ ) and dendritic arbor areas (median $=81,720 \mu \mathrm{m}^{2}$ ) are only marginally greater than at $P 1$, although dendritic coverage within individual cells has clearly increased. Since the number of primary dendrites is the same at $\mathrm{Pl}$ and $\mathrm{P} 6$, an overall increase in the median number of terminal segments per cell ( 32 at P1, 60 at P6) implies that most dendritic growth is due to interstitial branching from existing dendritic trunks. The photomicrographs in Figure 7, $C$ and $D$, show branching styles at P6 in detail. As at P1, a number of dendrites show exuberant, anisotropic elongation of terminal segments and arbors are yet to be restricted to discrete sublaminae within the inner plexiform layer.

By P12, adult cell types I, II, and III can be identified and ganglion cell numbers have reached their adult level. The majority of dendritic arbors are restricted to a single layer of the inner plexiform layer and dendritic spines are visible for the first time (Figs. $6 C 7 E$ ). Between $\mathrm{P} 6$ and $\mathrm{P} 12$, retinal area has more than tripled from $6.1 \pm 1.7 \mathrm{~mm}^{2}$ to $23.0 \pm 3.5 \mathrm{~mm}^{2}$, while median arbor area is approximately 10 times greater. Some dendritic and axonal features that are typical of more immature ganglion cells, still persist at P12: elongated dendritic terminal segments are still found in some cells (Fig. 6C) and club-like thickenings of some dendrites are reminiscent of growth cones. Supernumerary axons and highly convoluted axon loops close to the cell body are still visible in some cells; however, the short axonal spines or side-branches that were seen at P1 and $\mathrm{P} 6$ are no longer apparent.

Between P12 and P16, dendritic arbors display a continued elaboration of dendritic complexity at the finest level, while immature features such as multiple axons are lost. With no significant cell death in the population after P12 (Sengelaub and Finlay, 1982), it is logical to assume that these changes in morphology are due to plasticity in the processes, rather than addition or loss of individual cells. Very fine, filamentous processes visible at Pl4 (at high power in Fig. $7 F$ ), contribute to the extreme complexity of some of the dendritic arbors at this age (Fig. 6D). For the magnifications at which arbors arc rcconstructed, these processes lie at the extremes of resolution: their width is hence exaggerated in Figure $6 \mathrm{D}$. A notable feature of this phase in development are the varying number and distribution of spines on dendritic arbors. Spine density does not appear to correspond to any systematic variation in cell type. At P16, cells appear at their most elaborate (Fig. 6E), and in Figure 7, $G$ and $H$ compare the detailed morphology of a type I and type II arbor, respectively. Although uneven in distribution, both the length and the density of spines are at their greatest.

Following eye-opening at P15 or P16, retinal ganglion dendritic arbors across the range of cell types lose complexity. While spines may be retained in adulthood, no cells beyond P16 show the extreme degree of dendritic exuberance that is present before the eyes open. The ganglion cells at $\mathrm{P} 22$ in Figure $6 F$, have a comparable complexity to those in the adult animal (Fig. $2 A$ ). At high magnification (Fig. $7 I$ ), even where spines are still evident, their prominence is much reduced from extremes of elaboration seen at P16 (Fig. $7 G, H$ ).

Aberrant cells. An examination of the development of retinal ganglion cells with an aberrant projection (Fig. 8) reveals that, from P1 to P14, they display an entirely ordinary pattern of growth and diversity. At P1 (Fig. 8A) and P6 (Fig. 8B), aberrant cells show a full range of characteristic dendritic and axonal features that are associated with nonaberrant cells. Like ordinary cells, at P12 (Fig. 8C) and P14 (Fig. 8D), aberrant ganglion cells can be divided into adult types on the basis of their dendritic type and exhibit exuberant twigs and spines. However, at P16, the proportion of sparse dendritic morphologies dramatically increases. High-power photomicrographs of the spiny region of two complex P16 aberrant cells are shown in Figure $8, F$ and $G$, in contrast to that of a sparse arbor (Fig. $8 H$ ). Despite the difference in branching patterns, both complex and sparse arbors can display an equal degree of fine-scale spiny elaboration.

The time course of dendritic development, as measured by the fractal dimension, in ordinary and aberrant ganglion cells is illustrated in Figure 9. In ordinary cells (Fig. 9A), the even progression of changing dendritic complexity through early growth, the phase of peak complexity and subsequent remodeling, is clearly charted by the changing distributions of fractal dimensions in each age group. The quantitative dendritic development of aberrantly projecting cells (Fig. 9B), shows a very similar pattern up to P14, but subsequently the two populations diverge. At P16, the median fractal dimensions of aberrant cells $\left(D_{f}=1.253\right)$ and ordinary cells $\left(D_{f}=1.430\right)$ are already significantly different $(z=3.17 ; p=0.0016$, for a two-tailed WilcoxonMann-Whitney test), and this difference is maintained through to adulthood.

Aberrant cells are hence subjectively and quantitatively indistinguishable from ordinary cells beyond the completion of cell death (P12) and throughout the period of peak dendritic complexity (P14). Differences in this population seem to arise rapidly at P16 (day of cyc opening is either P15 or P16). Since the numbers of cells remains stable after P12, we assume that

\footnotetext{
Figure 6. The postnatal development of ordinary retinal ganglion cells is shown by representative drawings from serial photomicrographs. $A$, Cells at P1 show a characteristically sparse dendritic morphology with asymmetrical growth and a limited elaboration of major dendritic trunks. Axon side-branches and bifurcations are fairly common at this age and are marked with arrows. $B$, At P6 retinal ganglion cell arbors are more complex, but despite an evident diversity they do not fall into clear adult-like classes. Axonal bifurcations and side-branches are less apparent than at $\mathrm{P} 1$. Drawings of $\mathrm{P} 1$ and $\mathrm{P} 6$ cells are at the same magnification. A representative selection of cell types are shown at a lower power in $C$ ( $\mathrm{P} 12$ ), $D(\mathrm{P} 14), E(\mathrm{P} 16)$, and $F(\mathrm{P} 22)$. Adult cell types first become clear at $\mathrm{P} 12$, undergo a phase of dendritic elaboration (P12-P16) and then remodeling (P16-P22) as described in Results. Asterisks denote axons. Scale bar, $50 \mu \mathrm{m}$.
} 

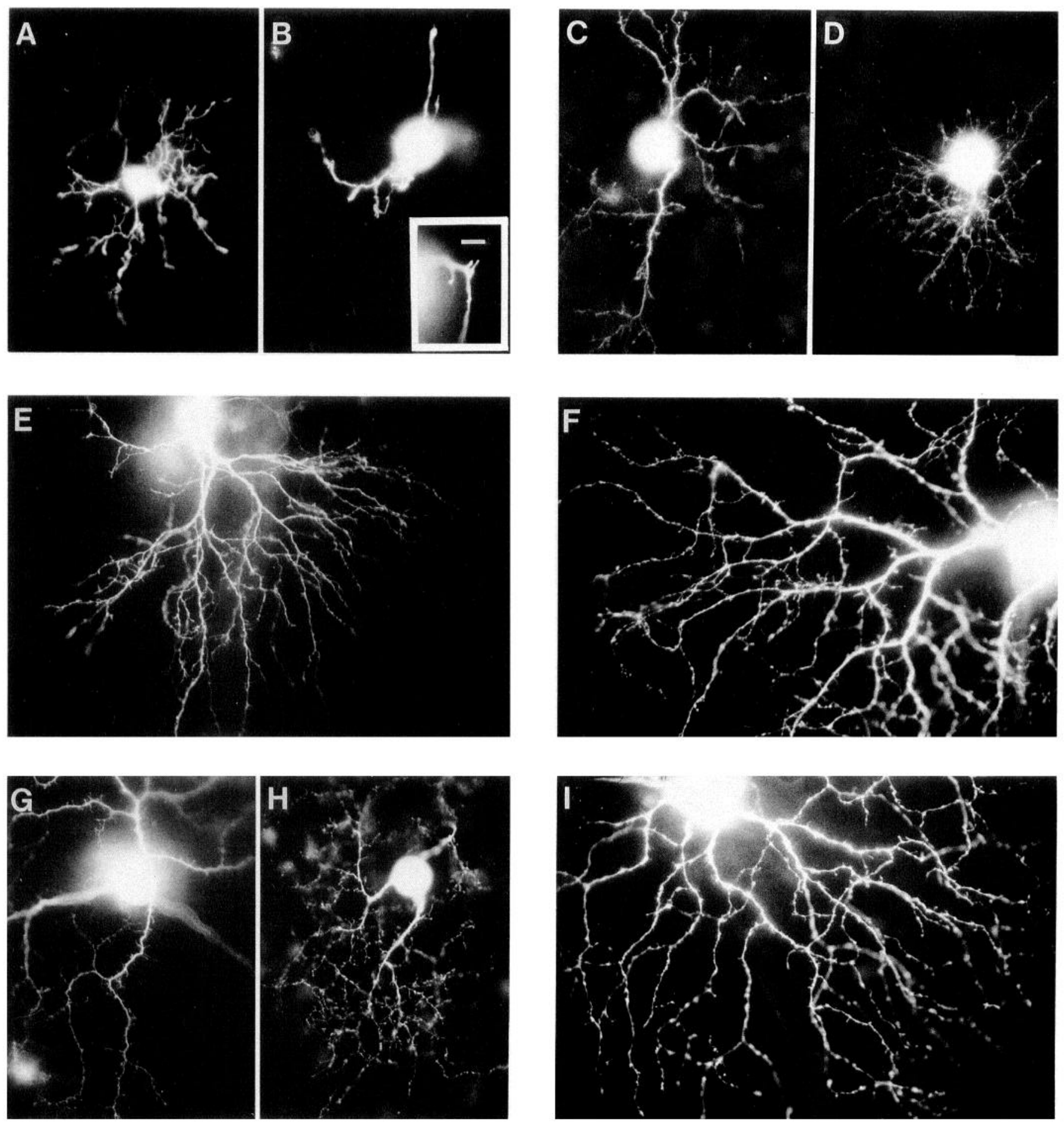

Figure 7. High-power photomicrographs of ordinary retinal ganglion cells at various postnatal ages. $A$ and $B$, Cells at P1 showing a limited degree of dendritic development. In $B$, the axon, which is out of focus in the main panel is shown at a higher power in the inset (scale bar, $5 \mu \mathrm{m}$ ). Three spines emerge from the axon trunk proximal to the cell body. $C$ and $D$, Cells at P6 showing immature but diverse dendritic phenotypes. $E$, P12 retinal ganglion cell of type I/II morphology. The arbor is asymmetric and the out of focus axon runs parallel to the orientation of the majority of dendrites. $F$, Type I cell at P14 whose dendrites are elaborated with thin filamentous branches in addition to dendritic spines. $G$ and $H$, Spiny dendritic arbors of P16 type I and type II cells, respectively. I, Type I dendritic arbor at P20 from which the majority of transient processes have been lost. Spines are retained and may persist to adulthood. Scale bar, $50 \mu \mathrm{m}$.

the predominant sparse aberrant phenotype is produced by an excessive, regressive remodeling of aberrant dendritic trees. This event correlates well with the time of eye-opening and hence the onset of patterned visual activity: is there a functional cor- relation between the emergence of the visuotopically aberrant phenotype and changes in the patterns of retinal activity? In the following section we compare the development of aberrant cells in normal hamsters with those from hamsters that have been 
raised in the dark over the period of ganglion cell dendritic remodeling.

\section{Aberrant dendritic development after P16 in normal and dark-reared animals}

Hamster pups were placed in the dark at P12, at the end of the period of death in the ganglion cell layer. Cell morphologies were examined at P22 and at P42, 1 week and 4 weeks after the eyes had opened. Figure 10 contrasts dendritic aberrant ganglion cell morphologies from normal and dark-reared hamsters at P22. Cells with an aberrant projection in normal hamsters (Fig. $10 A$ ) show a typically sparse dendritic morphology. By comparison, aberrant cells from dark-reared animals (Fig. 10B) have retained a diversity of complexity and range of cell types that is similar to that of ordinary cells. Figure $10, C$ and $D$, contrasts a normal and a dark-reared aberrant retinal ganglion cell of a similar soma and arbor size while the fine detail of their dendritic arbors shown at high power in Figure $10, E$ and $F$, respectively. Branching density is clearly lower in the aberrant cell from a normal hamster (Fig. 10C,E), but dendritic spines are present on both arbors. Similarly, between populations, while spines are retained on some dendritic arbors in both normal and darkreared populations, spine retention is not the basis of the observed differences. Rather, it appears that dark-rearing affects the degree of loss of major dendritic branches, while, just as in normal development, spininess is independent of cell type.

Quantitative parameters of aberrant cell morphology for normal and dark-reared hamsters at P22 are compared in Figure 11. There are no significant differences in the median values of arbor size and soma size. However, there is a substantially enhanced quantitative complexity in the dendritic trees in darkreared hamsters: the upper range of terminal segments per cell is obviously raised while median terminal segment number (per cell $=95$ ) is, in addition, more than twice the number in aberrant cells from normal hamsters (per cell $=41$; significant at $z=$ $3.80, p=0.001$, for a two-tailed Wilcoxon-Mann-Whitney test). Median dendritic coverage in dark-reared aberrant ganglion cells $\left(D_{f}=1.349\right)$ is also significantly greater than in aberrant cells from normal animals at P22 $\left(D_{f}=1.218 ; z=3.28, p=0.0001\right)$.

Does dark rearing simply delay the selective pruning of $a b$ errant cells? We examined retinal ganglion cells from hamsters that were dark reared to P42, the onset of sexual maturity, and found that the enhanced dendritic complexity of the aberrant population was maintained. The median dendritic complexity of aberrant cells from hamsters dark-reared to P42 $\left(D_{f}=1.313\right)$ is significantly higher than normal $(z=4.093, p<0.00006)$, and almost identical to that of ordinary hamster retinal ganglion cells.

\section{Summary}

The observations on changing complexity in hamster retinal ganglion cells are summarized in Figure 12. The median fractal dimensions of sample populations through development, in darkreared hamsters and in adult normal and monocularly enucleated animals are plotted with $95 \%$ confidence limits. The period of cell death is also shown (Sengelaub and Finlay, 1981, 1982; Insausti et al., 1984; Thompson, Cordery, and Holt, unpublished observations). It is clear that, simply in terms of overall dendritic complexity, the aberrant population diverges from ordinary cells only after cell death is complete. Both dark rearing (to P22 and P42) and monocular enucleation at P0 have significant effects on the differential regressive remodeling of $a b-$ errant cells that occurs after eye opening. The effects of eye removal at $\mathrm{P} 6$ and $\mathrm{P} 12$ are progressively less pronounced in the adult morphology of aberrant cells. We discuss the significance of these findings in terms of a possible retrograde mechanism as one component in the regulation of dendritic form.

\section{Discussion}

In this article we have examined factors that influence the development of hamster retinal ganglion cells. We describe how an initially diverse population of ganglion cells with a visuotopically aberrant projection is remodeled during normal development to produce an adult population that is characterized by a sparse dendritic morphology. The dendritic sculpting occurs after the period of ganglion cell death, around the time of eye opening. Dark rearing over this latter phase of remodeling, from P12 to P22, blocks the selective loss of complexity in aberrant cells. If dark rearing is maintained then the complexity of aberrant cells remains enhanced. The early diversity of ganglion cell morphology within the aberrant ipsilateral projection can also be stabilized by removing binocular competition for axonal terminal territory. When one eye is removed at $\mathrm{P} 0$, the aberrant population in the remaining eye of the adult En 0 hamster shows a full range of morphological types. The composition of the aberrant population shows progressively less diversity of form in an En6 hamster, and in the En 12 hamster, where the population closely resembles the aberrant projection in intact animals.

Both the freeing of axonal territory for the ipsilateral projection (by monocular enucleation within a sensitive period) and the prevention of patterned visual input (by dark rearing) dramatically alter the normal developmental pattern in visuotopically aberrantly projecting cells. We propose that aberrant cells develop a normally sparse dendritic morphology because they are functionally "downregulated" at eye opening. This conclusion and its consequences for understanding both the origins of retinal ganglion cell types and the role of retrograde factors in central neuron development, are fully discussed below.

\section{The status of the uncrossed projection from nasal retina}

Before considering our results, it is worth examining the nature of the retinal ganglion cell population that projects ipsilaterally from nasal retina. One interpretation is that these cells constitute developmental errors, reflecting some stochastic element in fiber routing at the chiasm. An alternative view is that the projection has a distinct, as yet unknown, function in adult visual systems. We consider the former explanation more probable. In terms of visual function, cells with an uncrossed projection from nasal retina cannot contribute to a congruent binocular visual map and their retinal coverage (estimated at 0.18 ) is very low. Therefore, they cannot form the coherent sampling mosaic that is classically seen as a requirement of a functional retinal ganglion cell class (Wässle et al., 1981). Developmentally, the population displays a diversity of morphological types at a time well after ganglion cell death is complete, suggesting that the apparently uniform adult morphology masks an initial plurality of ganglion cell type. This conclusion is strongly supported by the birthdating studies of Reese et al. (1992). In addition, during the period of ganglion cell death, many of the cells in the uncrossed projection from nasal retina are preferentially eliminated (Martin et al., 1983; Insausti et al., 1984; Jeffery, 1984), a fate that characterizes other cells with retinotopically inappropriate projections (O'Leary et al., 1986). 

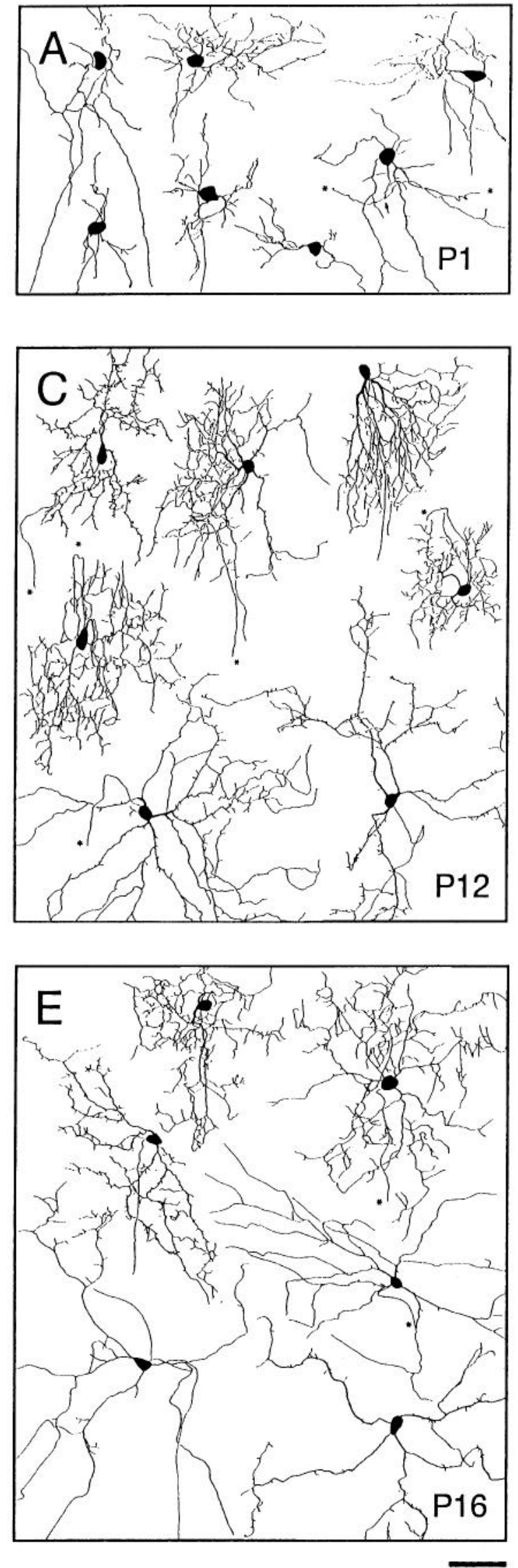
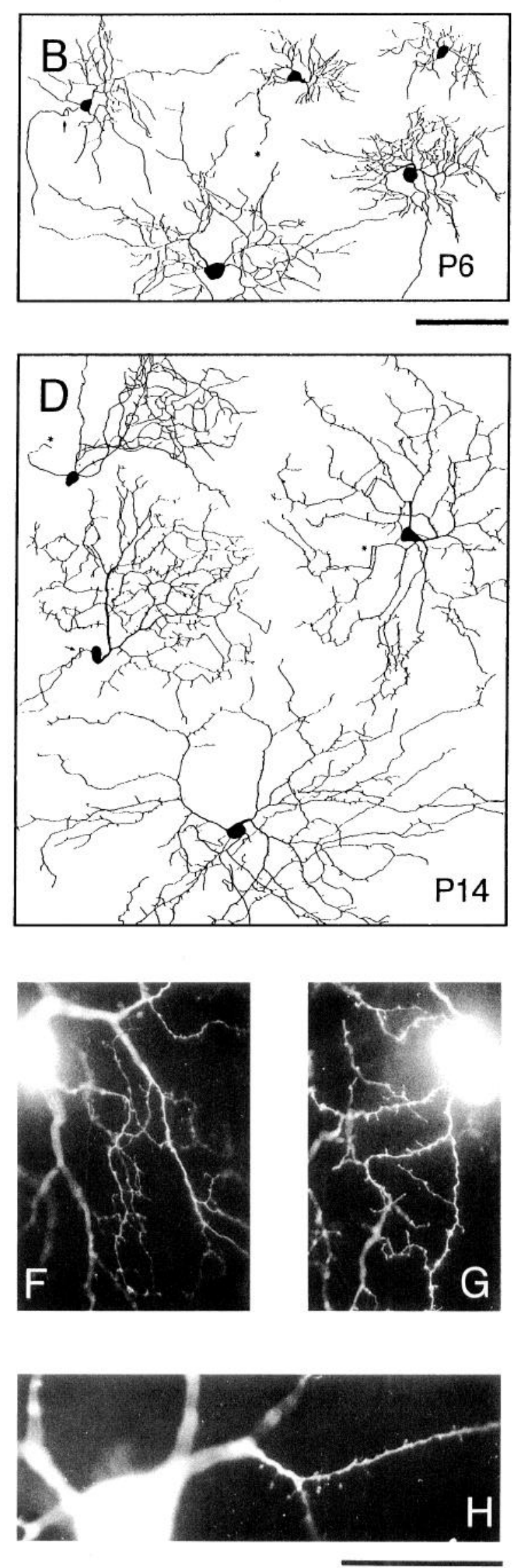
A final consideration is whether the uniformity of dendritic morphology of this projection in the intact adult reflects sampling errors. Any study that seeks to deduce a change across a population of cells from "snapshots" of isolated cohorts is compromised by whether it is consistently examining a representative sample of that population. For our study, the proportion of intracellularly filled cells within the relatively small aberrant nasal population is, in fact, reasonably high. The significant events in which we are interested occur only after the population has fallen to its adult size of around 200 cells. In any particular animal, up to $10 \%$ of all aberrant cells might be filled with Lucifer yellow in a single retina. By comparison, for the contralateral projection composed of ordinary ganglion cclls, this sample rate might be as low as 1 in 10,000 .

\section{The selective remodeling of aberrant ganglion cells and the effects of dark rearing}

One of the basic findings of this study is that the characteristic type III morphology of ganglion cells projecting ipsilaterally from adult nasal retina is generated, by the selective loss of dendrites, from an initially diverse range of morphologies. The early dendritic development of the aberrant population is indistinguishable from that of ordinary ganglion cells. There is a gradual increase in complexity up to P16 but subsequently, while ordinary cells show the subtle remodeling reported in other studies (Dann et al., 1987, 1988; Ramoa et al., 1987, 1988; Lau et al., 1992; Yamasaki and Ramoa, 1993; Wingate and Thompson, unpublished observations), aberrant cells are dramatically resculpted. As argued above, this process is unlikcly to reflect a sampling error, nor can it be explained by selective loss of cells-it occurs too late in development. Cell death in the ganglion cell population of the hamster is complete by eye opening (P12; by the number of degenerating cell bodies: Sengelaub and Finlay, 1981, 1982; and by retrograde tracer studies: Insausti et al., 1984; Thompson, Cordery, and Holt, unpublished observations; P16 by optic fiber counts: Tay et al., 1986) and can hence only affect the composition of populations before the period of dendritic pruning begins.

The normal remodeling of ordinary retinal ganglion cell dendrites is preceded by a phase in which processes are elaborated by smaller dendritic spines. This pattern, observed in other mammals (cat: Dann et al., 1987, 1988; Ramoa et al., 1987, 1988; rat: Perry and Walker, 1980; Yamasaki and Ramoa, 1993; hamster: Lau et al., 1992; ferret: Wingate and Thompson, unpublished observations), suggests that spine acquisition and dendritic remodeling are related. The retraction of spines does not appear to depend on normal patterns of retinal activity, as it occurs following dark rearing or intraocular injections of tetrodotoxin (Lau et al., 1990; Wong et al., 1991). Indeed, in our study, spines are equally well represented on cells from darkreared and normal hamsters at P22. However, dark rearing significantly alters the development of major dendritic branches
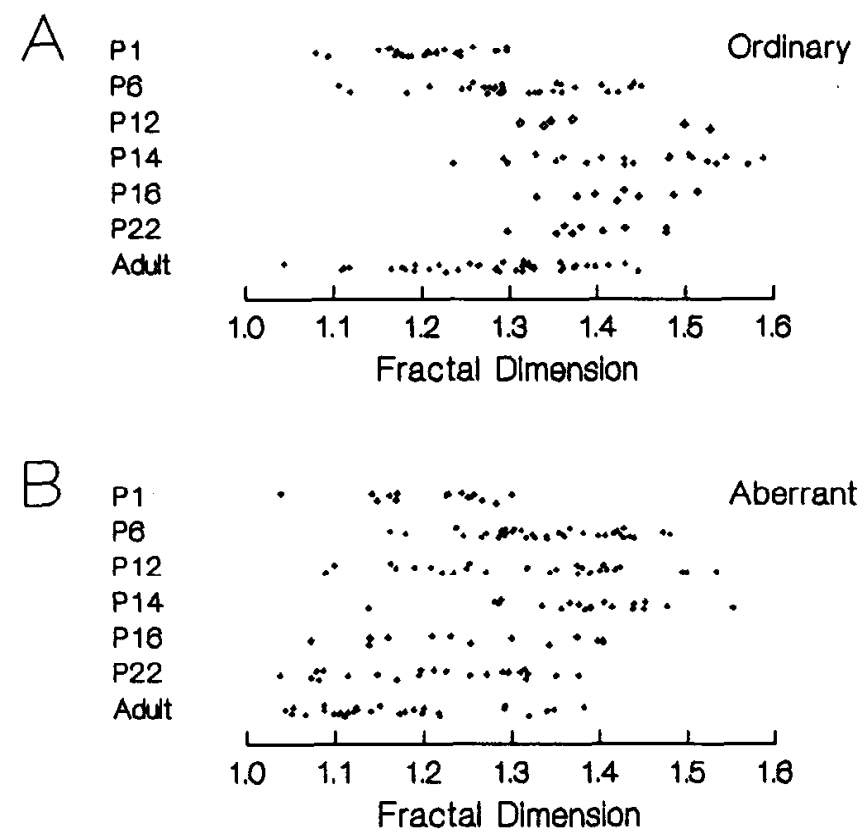

Figure 9. Density plots of fractal dimension at P1, P6, P12, P12, P16, $\mathrm{P} 22$, and adulthood for ordinary retinal ganglion cells $(A)$ and aberrant retinal ganglion cells $(B)$ with an ipsilateral projection from nasal retina. The fractal dimension for each cell within an age group is plotted along the $x$-axis. Displacement along the $y$-axis within each age group is "jittered" so that points do not overlap.

on retinal ganglion cells with visuotopically aberrant projections. The only other study linking significant changes in dendritic morphology with neural activity is that of Bodnarenko and Chalupa (1993), who have reported that blockade of glutamate receptors prevents the development of dendritic lamination patterns associated with ON- and OFF- ganglion cells.

Our observation that simple deprivation of light interferes with the normal modification of dendritic form allows us to speculate about the location of the regulating mechanism. By dark rearing from P12 to P22, the hamster is deprived of virtually all visually driven activity over the critical phase of retinal ganglion cell dendritic remodeling. For the vast majority of retinal ganglion cells this procedure produces no discernable effect (Lau et al., 1990). The dramatic effects of dark rearing on dendritic pruning are restricted to cells that are only distinguishable from their neighbors by the laterality of their axonal projection. Therefore, we suggest that the cues that trigger excessive dendritic remodeling in aberrant cells are derived axonally. By contrast, studies that have manipulated retinal ganglion cell density and hence "dendritic competition" report that interaction between neighboring ganglion cells in the retina can profoundly affect dendritic arbor shape (Perry and Linden, 1982; Eysel et al., 1985, Leventhal et al., 1988) and size (Bähr et al., 1992), but probably not complexity (Lau et al., 1991).

\footnotetext{
Figure 8. The development of aberrant retinal ganglion cells with an ipsilateral projection from nasal retina. $A$, $\mathrm{P} 1$ cells show characteristic features of early retinal ganglion cell dendritic and intraretinal axonal development. An arrow marks an intraretinal axonal bifurcation. Axons are marked with asterisks. $B$, Similarly at P6, small proximal intraretinal axonal side-branches are highlighted. Dendritic diversity is equivalent to that of ordinary cclls. Cclls at Pl and P6 are shown to the same magnification. $C$, Cells at P12, at a lower magnification, showing a full range of dendritic complexities. $D, \mathrm{P} 14$ aberrant retinal ganglion cell morphologies. A rare intraretinal axonal bifurcation is arrowed. $E$, Type I, II, and III aberrant retinal ganglion cells with an ipsilateral projection from nasal retina. The proportion of type III cells is higher than in an ordinary sample of cells. High-power photomicrographs of P16 aberrant cells are shown in the subsequent panels: $F$, type I cell; $G$, type II cell; and $H$, type III cell. All three dendritic types are covered with dendritic spines regardless of the overall dendritic complexity. Scale bars, $50 \mu \mathrm{m}$.
} 

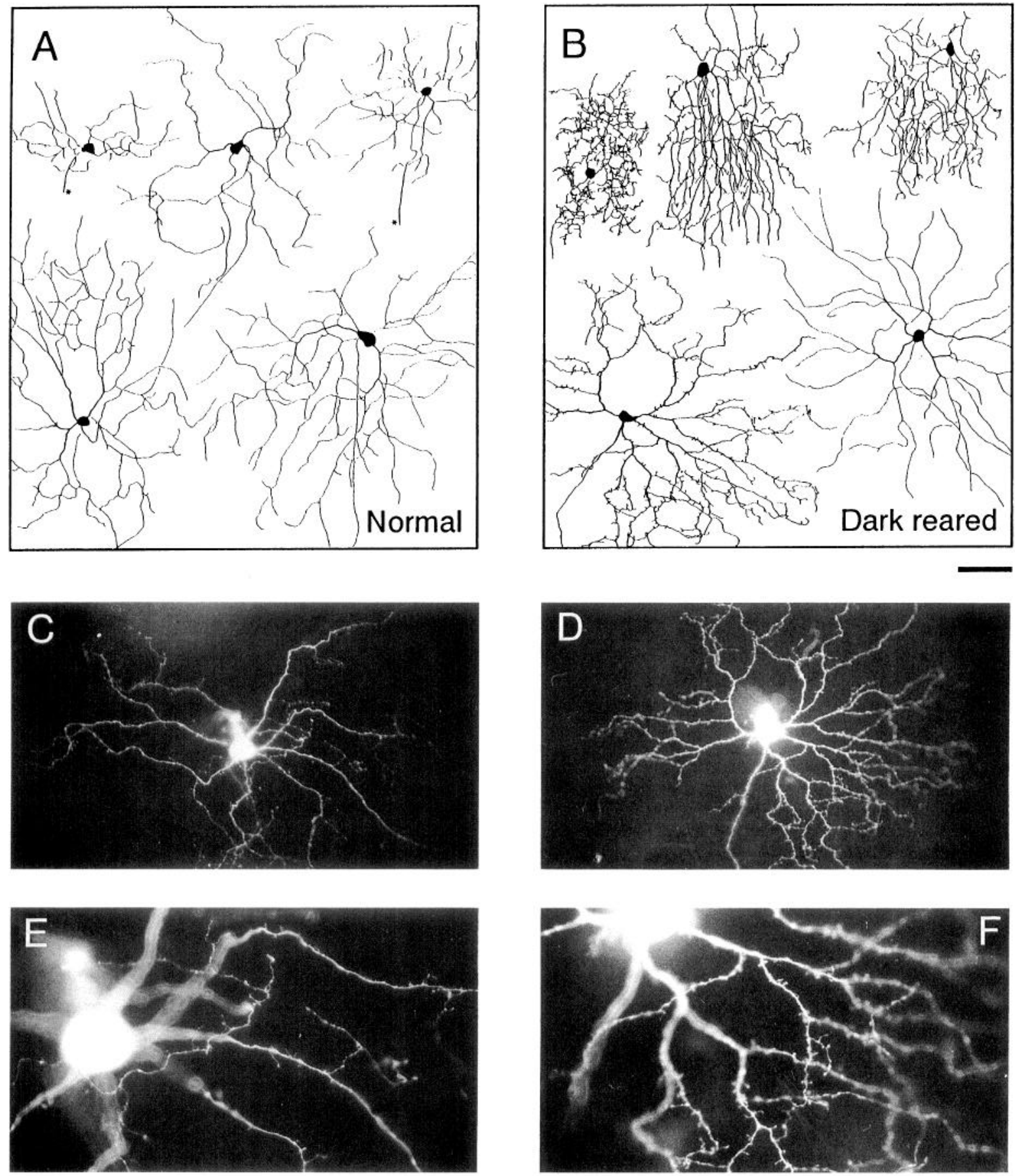

Figure 10. The effects of dark-rearing from P12-P22 on aberrant dendritic morphology. A, Aberrant cells from normal P22 hamsters show the normal, adult sparse morphology. $B$, Aberrant cells from dark-reared hamsters are considerably more dendritically complex and resemble ordinary retinal ganglion cells. Axons are marked with asterisks. Dark rearing was initiated at P12, after the reported period of death in the ganglion cell layer was complete (Sengelaub and Finlay, 1981, 1982; Insausti et al., 1984; I. D. Thompson, P. M. Cordery, and C. E. Holt, unpublished observations). $C$, Photomicrograph of a P22 aberrant cell from a normal hamster. $D$, Photomicrograph of a P22 aberrant retinal ganglion cell from a dark-reared hamster. High-power photomicrographs of the dendritic arbors of these two cells are shown in $E$, and $F$, respectively. Scale bars, 50 $\mu \mathrm{m}$.

While the long-term effects of dark rearing seem to indicate that a visual blockade can permanently block the selective remodeling of aberrant cells, further experiments are required to determine if this effect is reversible, or whether a sensitive period for dendritic remodeling exists as for dendritic competition (Eysel et al., 1985).

\section{Monocular enucleation and target interactions}

Superficially at least, the results of early enucleation are consistent with the hypothesis that interactions at the terminals influence the dendritic morphology of the aberrant retinal ganglion cells. Removal of one eye at birth in rodents leaves the 

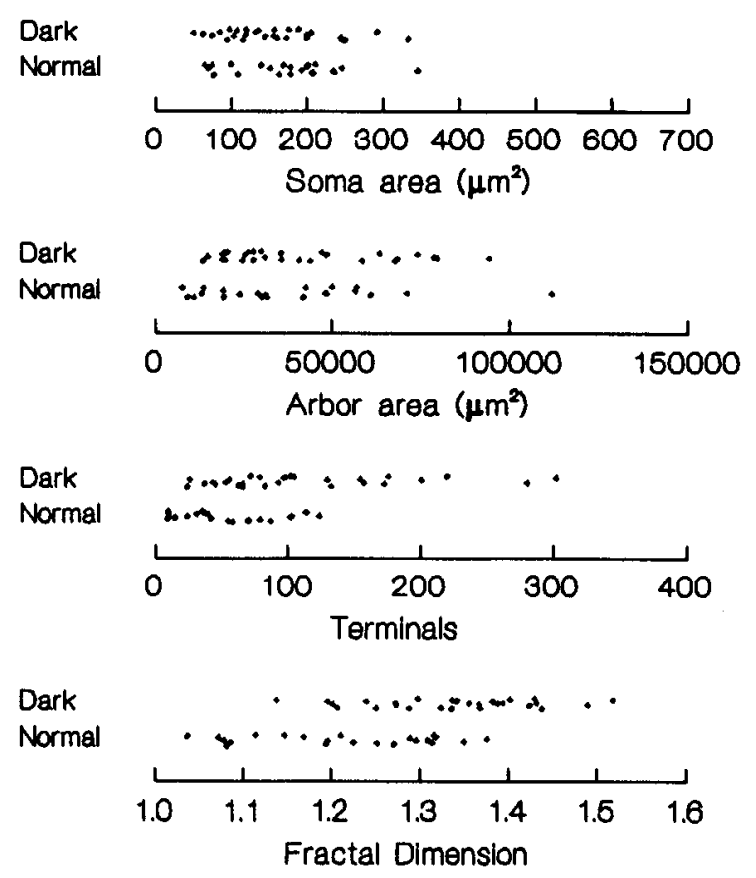

Figure 11. Density plots of soma area, arbor area, terminal segment number, and fractal dimension for aberrant cells from normal and darkreared hamsters at P22. The value for these parameters is plotted along the $x$-axis for each cell while the displacement along the $y$-axis within each sample groups is a randomized "jitter" to produce nonoverlapping points. Area and soma sizes are in $\mu \mathrm{m}^{2}$.

uncrossed retinal terminals expanded across the target nuclei. Physiologically, unlike an intact animal, it is possible to record receptive fields corresponding to inputs from nasal retina (Thompson, 1979; Rhoades, 1980; Jeffery and Thompson, 1986). The stabilization of initially exuberant connections in the En0 hamster is associated not only with a full complement of dendritic morphologies in the adult aberrant cell population, but also with increased numbers within this population. We would argue that dendritic diversity arises because terminal stabilization protects against later dendritic pruning at eye opening. However, the differential "rescue" of more complex ganglion cell types that might otherwise have died cannot be discounted as an explanation for the overall increase in aberrant dendritic complexity. The later the enucleation, the smaller is the number of rescued uncrossed ganglion cells and the smaller the incidence of aberrant ganglion cells with complex morphology. In En6 hamsters, the number of uncrossed cells is less than in an EnO animal but there is still terminal exuberance (Hsiao, 1984; Thompson, Cordery, and Holt, unpublished observations). Correspondingly, the overall dendritic complexity of aberrant cells is increased but not to the same degree as in an En0 hamster. Whether the absence of the most complex, type II, class in the En6 aberrant population is correlated with reduced exuberance in individual terminal arbors remains to be determined. It may be significant that the incidence of receptive fields activated through nasal retina in the uncrossed retinocollicular projection of En6 animals is much reduced (Thompson, unpublished observations). Enucleation at P12 in the hamster neither rescues cells nor results in an enlarged adult uncrossed projection (Hsiao, 1984; Thompson, Cordery, and Holt, unpublished observations) and has only trivial consequences for the morphology of aberrant cells.

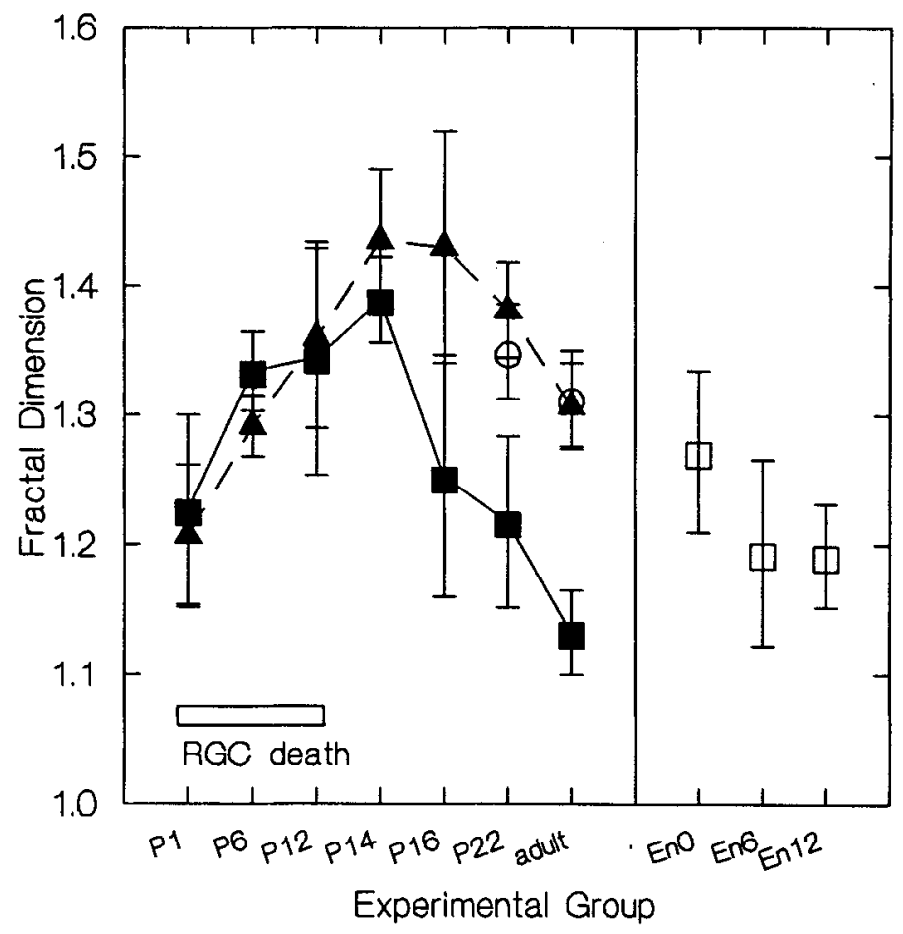

Figure 12. Plot of median fractal dimension for each sample group. Error bars represent $95 \%$ confidence limits about the median (McGill et al., 1978). To the left the changes in fractal dimension are plotted during development for ordinary $(\boldsymbol{\Lambda})$ and aberrant $(\square)$ populations. The approximate period of retinal ganglion cell death is shown as a horizontal bar. The median fractal dimension of aberrant ganglion cells from the retinas of dark-reared animals is also shown at P22 (O) and P42 (adult, $O)$. To the right the median complexity of aberrant cells is plotted for En0, En6, and En 12 monocular hamsters ( $\square$ ).

The absence of an effect of enucleation at P12 is apparently paradoxical given that we can manipulate aberrant cell dendritic development after this age by simply altering visual input. Is there a common mechanism that can explain the observed complexity of aberrant cells in both monocular and dark-reared hamsters? If on the one hand, it is solely differential cell rescue that causes increased complexity following early monocular enucleation, then these two results are indeed irreconcilable by a single mechanism: dark rearing after the period of cell death is complete (P12) cannot affect cell numbers. If, however, it is the degree of terminal exuberance that regulates eventual dendritic pruning, then increased aberrant dendritic complexity in monocular and dark-reared animals could be explained within a single model: both early removal of one eye and visual deprivation prevent a dendritic downregulation of aberrant cells, mediated by their axon terminals, that would normally occur at eye opening.

Finally, although binocular interactions may ultimately determine dendritic complexity in aberrant cells, they cannot be actively involved in the mechanism of dendritic modulation at eye opening: aberrant cells in En 12 and in intact adult hamsters undergo the same degree of remodeling regardless of input from the other eye. Hence the mechanism of retrograde dendritic pruning at eye opening would appear to be a monocular process. Indeed, by P12 the inputs from either eye have already segregated into distinct zones at the target (Frost et al., 1979; So ct al., 1984; Insausti et al., 1985; Woo et al., 1985). 


\section{A model for retrograde modulation of dendritic form}

In this study we show that an excessive degree of dendritic remodeling in aberrant cells depends on activity-related target interactions. While dark rearing and monocular enucleation at $\mathrm{P} 0$ both produce similar effects, it is not possible to determine whether the same mechanisms are involved. We hypothesize that the final degree of dendritic complexity for each aberrant cells may reflect the physical extent of its axonal arborization at the target. If a cell fails to gain adequate axonal synaptic connectivity through lack of correlated activity at the target, a retrograde signal that promotes dendritic remodeling is selectively enhanced in this cell. This has the effect, in normal retinas, of limiting synaptic input to the visual pathways from inappropriate sources. Such behavior has analogies in both the mechanisms that promote preferential loss of aberrantly projecting ganglion cells (Cowan et al., 1984; Fawcett et al., 1984; Thompson and Holt, 1989) and in processes that regulate cell numbers and dendritic complexity in the PNS (Purves et al., 1988; Voyvodic, 1989).

For ordinary ganglion cells with appropriate connectivity, the predominant determinant of dendritic coverage appears to be cell type that is intrinsic (Montague and Friedlander, 1989, 1991; Sakaguchi, 1989), while the role of retrograde modulation of dendritic form is negligible. However, the latter may have a general role in the fine-scale adjustment of retinal ganglion cell dendritic arbor complexities. It is possible that retrograde modulation ensures a consistent matching of terminal and dendritic extent across neighboring retinal ganglion cells. For the majority of cells, differences in the degree of dendritic fine tuning are relatively small. The effects that we have described have only been demonstrated in a population where topographic aberrancy, and hence its consequences for dendritic pruning, are exaggerated.

\section{Implications}

It is likely that cells that display other kinds visuotopic aberrancy will also be dendritically "downregulated" at eye opening. Preliminary results from Yamasaki and Ramoa (1989) indicate that cells that have appropriate decussation but then terminate at visually inappropriate sites within their target are predominantly of type III morphology in the adult, but are more diverse prior to eye opening. What proportion of extremely sparse dendritic types, variously classes as $\gamma$ (cat: Boycott and Wässle, 1974; ferret: Vitek et al., 1985), e (cat: Leventhal et al., 1980), or type III (Perry, 1979), are degenerate forms of more complex cell types that have aberrant projections? To what extent can the diversity within a heterogeneous class of cells, such as the ferret $\gamma$-cell (Wingate et al., 1992), be explained in terms of variable accuracy in topographic targeting?

Our results also have implications for the development of other mammalian central neurons. In general, target regulation of dendritic morphology to the degree demonstrated in the PNS (Purves et al., 1988; Voyvodic, 1989; Goldstein et al., 1993) has been ruled out in the CNS. Although cortical neurons may develop characteristic dendritic phenotypes through extensive dendritic remodeling (Koester and O'Leary, 1992; Vercelli et al., 1992), intrinsic explanations of dendritic diversity are preferred. Our results suggest that wherever dendritic exuberance is observed the influence of the target cannot be excluded in the formation of adult dendritic phenotypes. While the effect of retrograde modulation for the majority of cells is possibly neg- ligible, its consequences may be extreme for cells that deviate from a precise developmental "blueprint."

\section{References}

Archer SM, Dubin MW, Stark LA (1982) Abnormal development of kitten retino-geniculate connectivity in the absence of action potentials. Science 217:743-745.

Bähr M, Wizenman A, Thanos S (1992) Effect of bilateral tectum lesions on retinal ganglion cell morphology in rats. J Comp Neurol 320:370-380.

Bhide PG, Frost DO (1991) Stages of growth of hamster retinofugal axons: implications for developing axonal pathways with multiple targets. J Neurosci 11:485-504.

Bodnarenko SR, Chalupa LM (1993) Stratification of ON and OFF ganglion cell dendrites depends on glutamate-mediated afferent activity in the developing retina. Nature $364: 144-146$.

Boycott BB, Wässle H (1974) The morphological types of ganglion cells of the domestic cat's retina. J Physiol (Lond) 240:397-419.

Chalupa LM, Dreher B (1991) High precision systems require high precision "blueprints": a new view regarding the formation of connections in the mammalian visual system. J Cognit Neurosci 3:209219.

Cowan WM, Fawcett JW, O'Leary DDM, Stanfield BB (1984) Regressive events in neurogenesis. Science 225:1258-1265.

Dann JF, Buhl EH (1987) Retinal ganglion cells projecting to the accessory optic system in the rat. J Comp Neurol 262:141-158.

Dann JF, Buhl EH, Peichl L (1987) Dendritic maturation in cat retinal ganglion cells: a Lucifer yellow study. J Neurosci Lett 80:21-26.

Dann JF, Buhl EH, Peichl L (1988) Postnatal dendritic maturation of alpha and beta ganglion cells in cat retina. J Neurosci 8:1485-1499.

Eysel UT, Peichl L, Wässle H (1985) Dendritic plasticity in the early postnatal feline retina: quantitative characteristics and sensitive period. J Comp Neurol 242:134-145.

Fawcett JW, O'Leary DDM, Cowan WM (1984) Activity and the control of ganglion cell death in the rat retina. Proc Natl Acad Sci USA 81:5589-5593.

Flook AG (1978) The use of dilation logic on the quantimet to achieve fractal dimension characterisation of textured and structured $\% P$ profiles. Powder Technol 21:295-298.

Frost DO, So K-F, Schneider GE (1979) Postnatal development of retinal projections in Syrian hamsters: a study using autoradiographic and anterograde degeneration techniques. Neuroscience 4:1649-1677.

Fukuda Y, Morigiwa K, Tauchi M (1988) Morphology of alpha ganglion cells in the albino rat retina. Biomed Res [Suppl] 2:139-142.

Goldstein LA, Kurz EM, Kalkbrenner AE, Sengelaub DR (1993) Changes in dendritic morphology of rat spinal motorneurones during development and after unilateral target ablation. Dev Brain Res 73: 151-163.

Hahm J-O, Langdon RB, Sur M (1991) Disruption of retinogeniculate afferent segregation by antagonists to NMDA receptors. Nature 351: $568-570$.

Hsiao K (1984) Bilateral branching contributes minimally to the enhanced ipsilateral projection in monocular Syrian golden hamsters. $\mathbf{J}$ Neurosci 4:368-373.

Insausti R, Blakemore C, Cowan WM (1984) Ganglion cell death during development of ipsilateral retino-collicular projection in golden hamster. Nature 308:362-365.

Insausti R, Blakemore C, Cowan WM (1985) Postnatal development of the ipsilateral retinocollicular projection and the effects of unilateral enucleation in the golden hamster. J Comp Neurol 234:393-409.

Jeffery G (1984) Retinal ganglion cell death and terminal field retraction in the developing rodent visual system. Dev Brain Res 13:8196.

Jeffery G, Thompson ID (1986) The effects of prenatal and postnatal monocular enucleation on visual topography in the uncrossed retinal pathway to the rat superior colliculus. Exp Brain Res 63:351-363.

Kalil RE, Dubin MW, Scott G, Stark LA (1986) Elimination of action potentials blocks the structural development of retinogeniculate synapses. Nature 323:156-158.

Katz LC, Burkhalter A, Dreyer WJ (1984) Fluorescent latex microspheres as a retrograde neuronal marker for in vivo and in vitro studies in visual cortex. Nature 310:498-500.

Koester SE, O'Leary DDM (1992) Functional classes of cortical projection neurons develop dendritic distinctions by class-specific sculpting of an early common pattern. J Neurosci 12:1382-1393. 
Lau KC, So K-F, Tay D (1990) Effects of visual or light deprivation on the morphology, and the elimination of transient features during development, of type I retinal ganglion cells in hamsters. J Comp Neurol 300:583-592.

Lau KC, So K-F, Tay D, Jen LS (1991) Elimination of transient dendritic spines in ipsilaterally projecting retinal ganglion cells in rats with neonatal unilateral thalamotomy. Neurosci Lett 121:255-258.

Lau KC, So K-F, Tay D (1992) Postnatal development of type I retinal ganglion cells in hamsters: a Lucifer yellow study. J Comp Neurol 315:375-381

Leventhal AG, Keens J, Tork I (1980) The afferent ganglion cells and cortical projections of the retinal recipient zone (RRZ) of the cat's "pulvinar complex." J Comp Ncurol 194:535-554.

Leventhal AG, Schall JD, Ault SJ (1988) Extrinsic determinants of retinal ganglion cell structure in the cat. J Neurosci 8:2028-2038.

Mandelbrot BB (1977) The fractal geometry of nature. New York: Freeman.

Martin PR, Sefton AJ, Dreher B (1983) The retinal location and fate of ganglion cells which project to the ipsilateral superior colliculus in neonatal albino and hooded rats. Neurosci Lett 41:219-226.

McGill R, Tukey JW, Larsen WA (1978) Variations of box plots. Am Statistician 32:12-16.

Montague PR, Friedlander MJ (1989) Expression of an intrinsic growth strategy by mammalian retinal neurons. Proc Natl Acad Sci USA 86: 7223-7227.

Montague PR, Friedlander MJ (1991) Morphologies and territorial covcrage by isolated mammalian retinal ganglion cells. $J$ Neurosci 11:1440-1457.

O'Leary DDM, Fawcett JW, Cowan WM (1986) Topographic targeting errors in the retinocollicular projection, and their elimination by ganglion cell death. J Neurosci 6:3692-3705.

Peichl L (1989) Alpha and delta ganglion cells in the rat retina. J Comp Neurol 286:120-139.

Peichl L, Ott H, Boycott BB (1987) Alpha ganglion cells in mammalian retinae. Proc R Soc Lond [Biol] 231:169-197.

Perry VH (1979) The ganglion cell layer of the retina of the rat: a golgi study. Proc R Soc Lond [Biol] 204:363-375.

Perry VH, Linden R (1982) Evidence for dendritic competition in the developing retina. Nature 297:683-685.

Perry VH, Walker M (1980) Morphology of cells in the ganglion cell layer during development of the rat retina. Proc $R$ Soc Lond [Biol] 208:433-445.

Purves D, Snider WD, Voyvodic JT (1988) Trophic regulation of nerve cell morphology and innervation in the autonomic nervous system. Nature 336:123-128.

Ramoa AS, Campbell G, Shatz CJ (1987) Transient morphological features of identified ganglion cells in living fetal and neonatal retina. Science 237:522-525.

Ramoa AS, Campbell G, Shatz CI (1988) Dendritic growth and remodelling of cat retinal ganglion cells during fetal and postnatal development. J Neurosci 8:4239-4261.

Ramoa AS, Campbell G, Shatz CJ (1989) Retinal ganglion $\beta$ cells project transiently to the superior colliculus during development. Proc Natl Acad Sci USA 86:2061-2065.

Reese BE, Collelo RJ, Thompson WF (1992) Cell survival in the uncrossed projection of the mammalian retina is independent of birthdate. Eur J Neurosci 4:177-182.

Rhoades RW (1980) Effects of neonatal enucleation on the functional organization of the superior colliculus in the golden hamster. J Physiol (Lond) 301:383-399.

Sakaguchi DS (1989) The development of retinal ganglion cells deprived of their targets. Dev Biol 134:103-111.

Sengelaub DR, Finlay BL (1981) Early removal of one eye reduces normally occurring cell death in the remaining eye. Science 213:573574.

Sengelaub DR, Finlay BL (1982) Cell death in the mammalian visual system during normal development. i. Retinal ganglion cells. J Comp Neurol 204:311-317.
Shatz CJ, Stryker MP (1988) Prenatal tetrodotoxin infusion blocks segregation of retinogeniculate afferents. Science 242:87-89.

Siegel S, Castellan NJ Jr (1988) Nonparametric statistics for the behavioural sciences, 2d ed. New York: McGraw-Hill.

Simon DK, O'Leary DD (1992) Development of topographic order in the mammalian retinocollicular projection. J Neurosci 12:12121232.

So K-F, Woo HH, Jen LS (1984) The normal and abnormal development of retinogeniculate projections in golden hamsters: an anterograde horseradish peroxidase tracing study. Dev Brain Res 12 . 191-205.

Sretavan DW, Shatz CJ (1984) Prenatal development of individual retinogeniculate axons during the period of segregation. Nature 308: 845-848.

Sretavan DW, Shatz CJ, Stryker MP (1988) Modification of retinal ganglion cell axon morphology by prenatal infusion of tetrodotoxin. Nature 336:468-471.

Sur M, Humphrey AL, Sherman SM (1982) Monocular deprivation affects $\mathrm{X}$ - and $\mathrm{Y}$-retinogeniculate terminations in cats. Nature 300: 183-185.

Sur M, Weller RE, Sherman SM (1984) Development of X-and Y-cell retinogeniculate terminations in kittens. Nature 310:246-249.

Tay D, So K-F, Jen LS, Lau KC (1986) The postnatal development of the optic nerve in hamsters: an electron microscope study. Dev Brain Res 30:268-273.

Thompson ID (1979) Changes in the uncrossed retinotectal projection after the removal of one eye at birth. Nature 279:63-66.

Thompson ID, Holt CE (1989) Effects of intraocular tetrodotoxin on the development of the retinocollicular pathway in the Syrian hamster. J Comp Neurol 282:371-388.

Vercelli A, Assal F, Innocenti GM (1992) Emergence of callosally projecting neurons with stellate morphology in the visual cortex of the kitten. Exp Brain Res 90:346-358.

Vitek DJ, Schall JD, Leventhal AG (1985) Morphology, central projections, and dendritic field orientation of retinal ganglion cells of the ferret. J Comp Neurol 241:1-11.

Voyvodic JT (1989) Peripheral target regulation of dendritic geometry in the rat superior cervical ganglion. J Neurosci 9:1997-2010.

Wässle H (1988) Dendritic maturation of retinal ganglion cells. Trends Neurosci 11:87-89.

Wässle H, Peichl L, Boycott BB (1981) Dendritic territories of cat retinal ganglion cells. Nature 292:344-345.

Wingate RJT, Thompson ID (1989) The morphology of aberrant mammalian retinal ganglion cells. Soc Neurosci Abstr 15:457.

Wingate RJT, Fitzgibbon T, Thompson ID (1992) Lucifer yellow, retrograde tracers, and fractal analysis characterise adult ferret retinal ganglion cells. J Comp Neurol 323:449-474.

Wong ROL (1990) Differential growth and remodelling of ganglion cell dendrites in the postnatal rabbit retina. J Comp Neurol 294:109132.

Wong ROL, Herrmann K, Shatz CJ (1991) Remodelling of retinal ganglion cell dendrites in the absence of action potential activity. $J$ Neurobiol 22:685-697.

Wong ROL, Yamawaki RM, Shatz CJ (1992) Synaptic contacts and the transient dendritic spines of developing retinal ganglion cells. Eur J Neurosci 4:1387-1397.

Woo HH, Jen LS, So K-S (1985) The postnatal development of normal retinocollicular projections in hamsters and in hamsters following neonatal monocular enucleation: a horseradish peroxidase tracing study. Dev Brain Res 20:1-13.

Yamasaki EN, Ramoa AS (1989) Dendritic development of abnormally projecting rat retinal ganglion cells. Soc Neurosci Abstr 16:334.

Yamasaki EN, Ramoa AS (1993) Dendritic remodelling of retinal ganglion cells during the development of the rat. J Comp Neurol 329: 277-289. 